\title{
Observations during suction bucket installation in sand
}

\section{Raffaele Ragni PhD}

Research Associate, Centre for Offshore Foundation Systems and ARC COE for Geotechnical Science and Engineering, University of Western Australia, Crawley, Perth, WA, Australia (corresponding author:

raffaele.ragni@uwa.edu.au)

\section{Britta Bienen PhD}

Associate Professor, Centre for Offshore Foundation Systems and ARC COE for Geotechnical Science and Engineering, University of Western Australia, Crawley, Perth, WA, Australia

\section{Samuel Stanier PhD}

University Senior Lecturer, Centre for Offshore Foundation Systems and ARC CoE for Geotechnical Science and Engineering, University of Western Australia, Crawley, Perth, WA, Australia; Cambridge University Engineering Department, Cambridge, UK

\section{Conleth O'Loughlin PhD}

Associate Professor, Centre for Offshore Foundation Systems and ARC COE for Geotechnical Science and Engineering, University of Western Australia, Crawley, Perth, WA, Australia

\section{Mark Cassidy PhD}

Professor, Melbourne School of Engineering, University of Melbourne, Victoria, Australia

Suction buckets represent a viable solution as foundations for offshore wind turbines. Installation in sand is relatively straightforward, albeit with limited understanding of the resulting changes in soil state. This paper describes an experimental methodology that allows for visualisation and quantification of changes in soil state during suction bucket installation, validated in sand. Insights obtained from particle image velocimetry analyses, performed on images of a half-bucket installing against a Perspex window taken in a geotechnical centrifuge are discussed. Compared with the initial self-weight penetration, the deformation mechanism governing the suctionassisted phase shows a preference for the soil below the skirt tips to move inwards and upwards inside the bucket. The installation process is responsible for changes in relative density and permeability within the bucket. In these experiments, the majority of the soil plug heave can be attributed to the soil displaced inwards by the advancing skirts, with a minor contribution caused by dilation. The confidence in the experimental methodology provided through the results of suction bucket installation in sand discussed herein now enables suction bucket installation in more complex seabeds to be investigated.

\section{Notation}

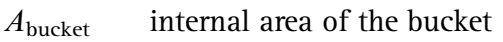

$\mathrm{CC}_{\mathrm{ZNCC}}$ zero normalised cross-correlation coefficient

D bucket diameter

$D_{\mathrm{m}} \quad$ model-scale bucket diameter

$D_{\mathrm{p}} \quad$ prototype-scale bucket diameter

$D_{\mathrm{r}} \quad$ sand relative density

$d_{50} \quad$ mean particle size

e void ratio

$e_{\max }$

$e_{\min }$

$G_{\mathrm{s}}$

g

$h_{\text {dil }}$

$h_{\text {plug }}$

$h_{\text {skirt }}$

$K_{0}$

$k$

$L$

$N$

$q_{\mathrm{c}}$ $r$

$t$

$V_{\text {s-w }} \quad$ self-weight vertical load

$z \quad$ penetration depth

$\dot{z} \quad$ bucket penetration rate

$z_{\text {fin }} \quad$ final skirt penetration

$z_{\text {PIV }} \quad$ depth of the PIV analysis

$z_{\text {S-w }} \quad$ self-weight embedment

$\gamma_{\mathrm{s}} \quad$ total shear strain

$\Delta z_{\mathrm{PIV}} \quad$ penetration analysed with PIV analysis

$\varepsilon_{\mathrm{v}} \quad$ total volumetric strain

$\rho_{\max } \quad$ maximum dry density

$\rho_{\text {min }} \quad$ minimum dry density

$\phi_{\mathrm{cv}}^{\prime} \quad$ critical state friction angle

\section{Introduction}

The concept of a suction bucket foundation was first adopted in the 1980s for the foundations of fixed offshore structures (Senpere and Auvergne, 1982), with application predominantly within the oil and gas industry (e.g. Bye et al., 1995; Tjelta, 
International Journal of Physical Modelling in Geotechnics Volume 20 Issue 3
Observations during suction bucket installation in sand

Ragni, Bienen, Stanier, O'Loughlin and Cassidy
2015). Suction bucket technology is increasingly regarded with interest for the foundations of offshore wind farms (e.g. Ehrmann et al., 2016; Houlsby, 2016). Advantages include silent and rapid installation. When compared with the oil and gas industry, current wind farm applications are limited to shallow waters, typically less than $60 \mathrm{~m}$ depth, with predominantly sandy seabeds (Shonberg et al., 2017; Sturm, 2017).

Suction buckets comprise a large diameter steel cylinder, openended at the bottom and closed at the top. A valve allows the control of flow of water through the lid and application of differential pressure. For offshore wind turbine applications, suction bucket geometries are expected to have a skirt length, $L$, that is no greater than the bucket diameter, $D$ - that is, $L / D \leq 1$ (Tjelta, 2015). Turbines can be founded either on a monopod with a single bucket, or on a jacket with multiple buckets.

Initial penetration in the seabed is achieved under the submerged self-weight of the bucket. Following refusal under selfweight, a differential pressure (here referred to as suction, even though the pressure is in fact always positive) is applied across the lid that drives the suction bucket in further (Houlsby and Byrne, 2005a). In sand, suction causes significant seepage flow (due to the relatively high permeability), which reduces effective stresses around the skirt tips, facilitating further penetration (Erbrich and Tjelta, 1999; Houlsby and Byrne, 2005b). Established methods for the prediction of the required suction for installation in sand do exist (Andersen et al., 2008; Houlsby and Byrne, 2005b; Senders and Randolph, 2009), although some of the resulting changes in soil state as well as heave of the soil plug confined within the skirt are not well understood.

This study describes an experimental methodology for the investigation of suction bucket installation. The approach is validated using the reference case of a sandy seabed, allowing future investigations of more complex, layered profiles. The study visually captures the processes that occur both within the bucket interior and in the soil outside the bucket skirts, and provides certainty for installation prediction methods developed for sand, which require a priori assumptions regarding changes in soil state. In particular, the results for this reference sand seabed profile

(a) allow identification of the deformation mechanisms underlying bucket installation (and compare the self-weight and suction-assisted phases)

(b) offer insights into the changes in soil state resulting from suction bucket installation

(c) improve understanding of the causes - and allow quantification of the magnitude - of soil plug heave and (d) allow determination of the effect of key parameters on the resulting changes in soil state and extent of soil plug heave, such as applied pumping flow rate, initial sand relative density and soil stress level.

Particle image velocimetry (PIV) measurements performed in a geotechnical centrifuge (e.g. Stanier et al., 2015) underpinned this study, such that the insights gained reflect prototype behaviour due to inherent stress similitude and appropriately scaled drainage properties. The observations build on the previous model scale experiments conducted at single gravity by Tran et al. (2005) and Kim et al. (2017). The results extend beyond identification of deformation mechanisms, and include estimation of changes in soil state based on interpretation of volumetric and shear strain fields.

\section{Experimental arrangement and procedure}

\subsection{Centrifuge set-up}

The experiments presented in this paper were performed at $100 \mathrm{~g}$ or $40 \mathrm{~g}(N=100$ or 40$)$ in the $1.8 \mathrm{~m}$ Actidyn C661 beam centrifuge at the University of Western Australia (Randolph et al., 1991; Randolph and Gaudin, 2017).

Figure 1(a) shows an overview of the experimental set-up adopted. A centrifuge sample container, referred to as a 'strongbox', was used to house a smaller PIV strongbox (with inner dimensions of $335 \times 225 \times 300 \mathrm{~mm}$ ) that contained the sand sample. One face of the PIV strongbox had a $50 \mathrm{~mm}$ thick transparent acrylic window (to facilitate the PIV measurements); the thickness was selected to limit the lateral deflection following ramp-up at $100 \mathrm{~g}$ to a tolerable value (Haigh and Madabhushi, 2014), and guaranteed a negligible effect on sand density and $K_{0}$ conditions in the sample. An array of regularly spaced, pre-installed control markers on the window (Figure 1(b)) was also required for the photogrammetric correction of the measurements (i.e. conversion from pixels to engineering units; in this case $\mathrm{mm}$ ). An electrically driven actuator, connected to the suction bucket model through a steel shaft and a $2 \mathrm{kN}$ axial load cell, allowed independent control of the foundation in the vertical and horizontal degrees of freedom. A three-way valve positioned on the suction bucket lid (Figure 1(c)) allowed: (a) fluid flow to be vented to ambient; $(b)$ suction to be applied by way of a flexible pipe that was connected to a syringe pump mounted on the exterior of the centrifuge strongbox and $(c)$ the foundation to be sealed against the transparent strongbox window (as required for a successful suction-assisted installation). The three-way valve was operated remotely using a winch motor and wire arrangement (see Bienen et al., 2018 for further details). The suction bucket was instrumented with a $100 \mathrm{kPa}$ Honeywell differential pore-pressure sensor at the lid invert 
International Journal of Physical Modelling in Geotechnics Volume 20 Issue 3
Observations during suction bucket

installation in sand

Ragni, Bienen, Stanier, O'Loughlin and

Cassidy

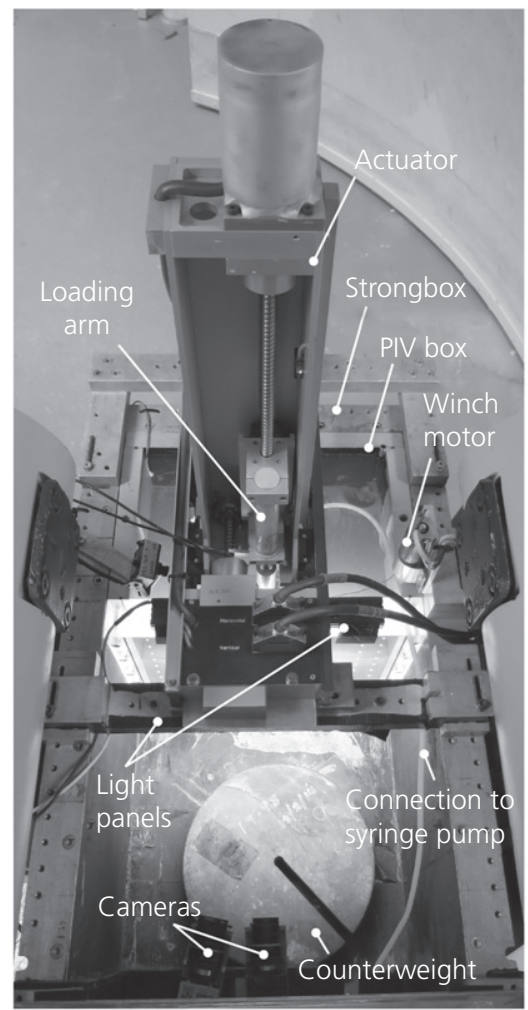

(a)
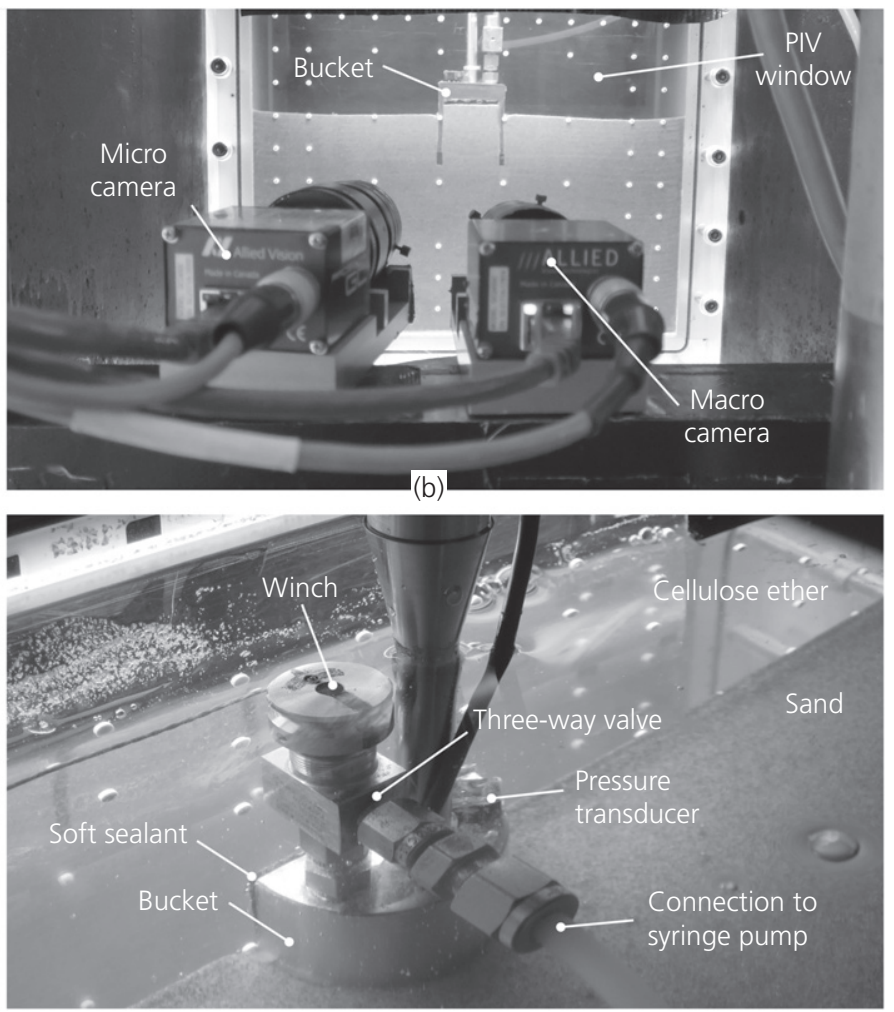

(c)

Figure 1. Illustration of the centrifuge experimental apparatus

that measured the difference in pressure across the lid. A $20 \mathrm{~kg}$ counterweight positioned on the opposite side of the PIV strongbox balanced the payload on the swinging platform at $100 \mathrm{~g}$. Two 5-megapixel machine vision cameras were positioned opposite the PIV window on a rigid cross-bar to capture images for the PIV analyses (Figure 1(b)). The master 'macro' camera ( $8 \mathrm{~mm}$ lens) provided a view of the entire window, whereas the slave 'micro' camera (43 mm lens) focused on the region around the bucket skirts, providing highly detailed images (at $\sim 20$ times the effective resolution of the 'macro' camera) of this region of interest. This highresolution 'micro' camera was necessary for capturing sufficiently detailed images so as to measure localised volume changes in the sand, whereas the 'macro' camera allowed the plug heave to be tracked when this left the limited field of view of the 'micro' camera. The cameras captured images at a rate of 2 frames/s throughout each test. Two panels of lightemitting diode (LED) lights provided a sufficient and even illumination on the front face of the model (see Teng et al., 2017 for more details on the general camera and lighting set-up).

This study used a suction bucket model with diameter $D_{\mathrm{m}}=50 \mathrm{~mm}$, and different centrifuge acceleration levels
$(N=40$ and 100), allowing investigation of prototype effective stresses corresponding to buckets with diameters, $D_{\mathrm{p}}=2$ and $5 \mathrm{~m}$. The model had a skirt length, $L=D$ to maximise the depth of suction-assisted penetration while at the same time maintaining suction bucket geometries that are typical for shallow water applications.

Maintaining the seal at the interface between the suction bucket and the PIV window was crucial for successful suction bucket installation and validity of the tests as seepage flow in the prototype occurs through the sand. For this reason, a skirt thickness, $t=2 \mathrm{~mm}$ - that is, a ratio $D / t=25$, was adopted. A smaller skirt thickness would have resulted in a seal that was too fragile to survive the full penetration process. Although lower than typical $D / t$ values, which may be closer to 200, Tran and Randolph (2008) demonstrated that the skirt thickness has only a marginal effect on the suction required during installation. Furthermore, Garnier et al. (2007) indicate that grain-size effects are not significant for shallow footings when the ratio of the significant model dimension over the mean particle size, $t / d_{50}>35$. In the experiments presented in this paper shows $t / d_{50} \sim 11$. While this does not meet the Garnier et al. (2007) $t / d_{50}>35$ threshold, it is worth noting that: (i) this 
International Journal of Physical Modelling in Geotechnics Volume 20 Issue 3
Observations during suction bucket installation in sand

Ragni, Bienen, Stanier, O'Loughlin and Cassidy criterion was established for shallow footings and there is no equivalent established threshold for a deeply buried footing, (ii) Tran (2005) showed that almost doubling the $t / d_{50}$ ratio for a suction bucket led to no observable difference in the penetration resistance and (iii) $t / d_{50}=35$ would require a skirt thickness, $t=6.3 \mathrm{~mm}$, such that maintaining geometrical similitude with the equivalent prototype would require a model bucket with a diameter, $D=1260 \mathrm{~mm}$ (adopting $D / t=200$ ). This last point in particular is evidently impractical. Hence, there is a balance to be struck between avoiding potential particle-size effects and maintaining geometrical similitude. This study required a larger skirt thickness to ensure sealing of the skirts against the PIV window, such that the $t / d_{50}$ ratio is higher than the bulk of the previous experimental effort in this area (e.g. $t / d_{50}=3 \cdot 3$ in Bienen et al., 2018 and $t / d_{50}=1 \cdot 7-3 \cdot 3$ in Tran and Randolph, 2008). Hence, any potential particlesize effects will be less pronounced in our study than in previous experimental studies.

A combination of soft sealant closed-cell foam tape was applied on the majority of the interface and hard rubber at the bucket tips (Figures 1(c) and 2), which were adequately lubricated with petroleum jelly before each test. This provided: (i) sealing of the bucket interior from the external fluid; (ii) sufficient resistance against peeling of the foam tape during installation (improved by the presence of the hard rubber strips at the skirt tip); and (iii) minimal friction generation during suction bucket installation. The horizontal degree of freedom
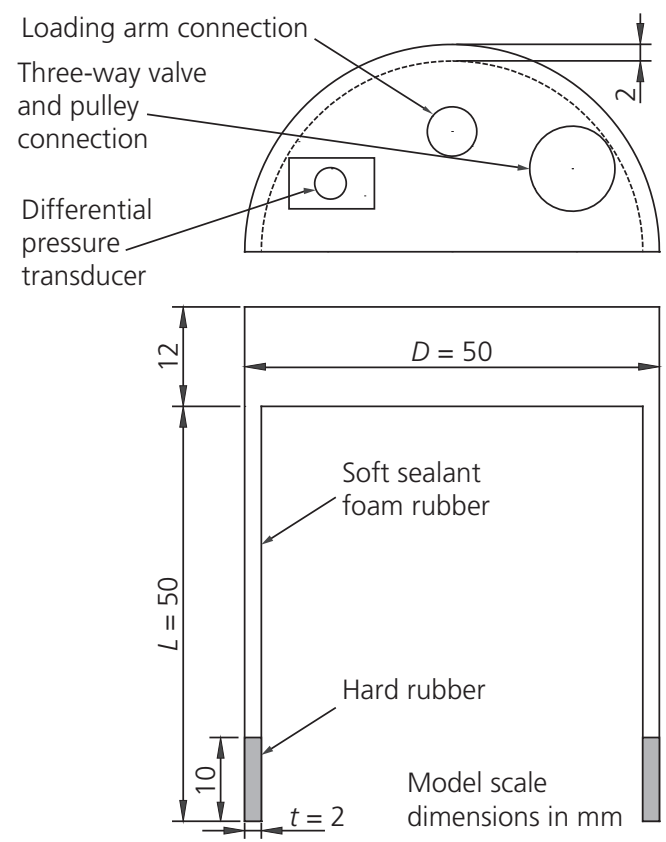

Figure 2. Schematic of the suction bucket model of the actuator allowed the pressure of the suction bucket model against the PIV window to be optimised, while minimising the contact friction.

Details of the geometry of the aluminium model used in this centrifuge experimental campaign are shown in Figure 2.

\subsection{Soil sample}

Table 1 provides a summary of the properties of the very fine silica sand used in this investigation. Each sample was prepared by pluviating the silica sand into the PIV strongbox, either from an automated sand rainer (for dense samples) or by hand (for the medium dense sample). In order to obtain the optimal particle contrast required for high-quality PIV analyses, $25 \%$ dyed (black) sand was mixed with $75 \%$ untreated natural sand. A drainage layer of $10 \mathrm{~mm}$ coarse sand overlain by a layer of geotextile was placed at the base of the PIV strongbox prior to pluviation to facilitate saturation from the base of the sample. Each sample height was $175 \mathrm{~mm}$. The relative density $D_{\mathrm{r}}$ of each dense sample was calculated from measurements of total sample mass and volume, with values

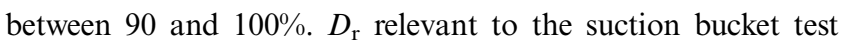
for the medium dense sample (test 5) was established to be $\sim 45 \%$ from correlation with the cone tip resistance $q_{\mathrm{c}}$ (Schneider and Lehane, 2006).

The samples were saturated on the laboratory floor at $1 \boldsymbol{g}$ with a solution of water and $1.4 \%$ or $1 \cdot 1 \%$ cellulose ether, to obtain a viscosity of 100 or $40 \mathrm{cSt}$, respectively (DOV (Dow, 2002)), while measurement of the free fluid temperature in the PIV strongbox during the tests confirmed a constant value of $20 \pm 1^{\circ} \mathrm{C}$. Matching the viscosity with the target centrifuge acceleration level was necessary to correctly scale the drainage properties of the soil (Bienen et al., 2018; Dewoolkar et al., 1999; Tan and Scott, 1985; Taylor, 1987). Sample saturation was achieved through the base of the PIV strongbox. Care was taken to ensure that the fluid reservoir elevation was sufficiently low to prevent piping in the sample. The tests started with a fluid head above the sample of $\sim 125 \mathrm{~mm}$.

Cone penetrometer tests (CPTs) were performed at the centrifuge testing acceleration in the centre of each sample - that is, at a distance of $\sim 112.5 \mathrm{~mm}$ from the PIV window and $\sim 150 \mathrm{~mm}$ from the side walls. Hence, the closest rigid boundary is at a distance of 16 cone diameters, greater than the minimum ten diameters recommended in Bolton et al. (1999) to minimise potential boundary effects. A model scale penetrometer with a diameter of $7 \mathrm{~mm}$ was penetrated at a constant velocity of $1 \mathrm{~mm} / \mathrm{s}$. This provided a basis for characterising the samples and quantifying potential density variations between samples. Typical profiles of cone tip resistance, $q_{\mathrm{c}}$ with normalised depth, $z / L$ (adopting $L=50 \mathrm{~mm}$ ) are provided in Figure 3, 
International Journal of Physical Modelling in Geotechnics Volume 20 Issue 3
Observations during suction bucket

installation in sand

Ragni, Bienen, Stanier, O'Loughlin and

Cassidy

Table 1. Silica sand properties

\begin{tabular}{|c|c|c|c|c|c|c|c|}
\hline $\begin{array}{l}\text { Specific } \\
\text { gravity } \\
\mathbf{G}_{\mathrm{s}}:-\end{array}$ & $\begin{array}{c}\text { Mean } \\
\text { particle } \\
\text { size } d_{50}: \mathrm{mm}\end{array}$ & $\begin{array}{l}\text { Minimum } \\
\text { dry density } \\
\rho_{\min }: \mathrm{kg} / \mathrm{m}^{3}\end{array}$ & $\begin{array}{l}\text { Maximum } \\
\text { void ratio } \\
e_{\max }:-\end{array}$ & $\begin{array}{l}\text { Maximum } \\
\text { dry density } \\
\rho_{\text {max }}: \mathrm{kg} / \mathrm{m}^{3}\end{array}$ & $\begin{array}{l}\text { Minimum } \\
\text { void ratio } \\
e_{\text {min }}:-\end{array}$ & $\begin{array}{c}\text { Critical state } \\
\text { friction angle } \\
\phi_{\text {cv: }}^{\prime}{ }^{\circ}\end{array}$ & $\begin{array}{c}\text { Permeability (water } \\
\text { saturated) } k_{\mathrm{w}}: \mathrm{m} / \mathrm{s} \\
D_{\mathrm{r}}=100 \% 145 \%\end{array}$ \\
\hline $2 \cdot 67$ & $0 \cdot 18$ & 1497 & 0.784 & 1774 & 0.505 & $31 \cdot 6$ & $1.0 \times 10^{-4} \mid 1.7 \times 10^{-4}$ \\
\hline
\end{tabular}

Source: After Chow et al. (2018) and Tran (2005)

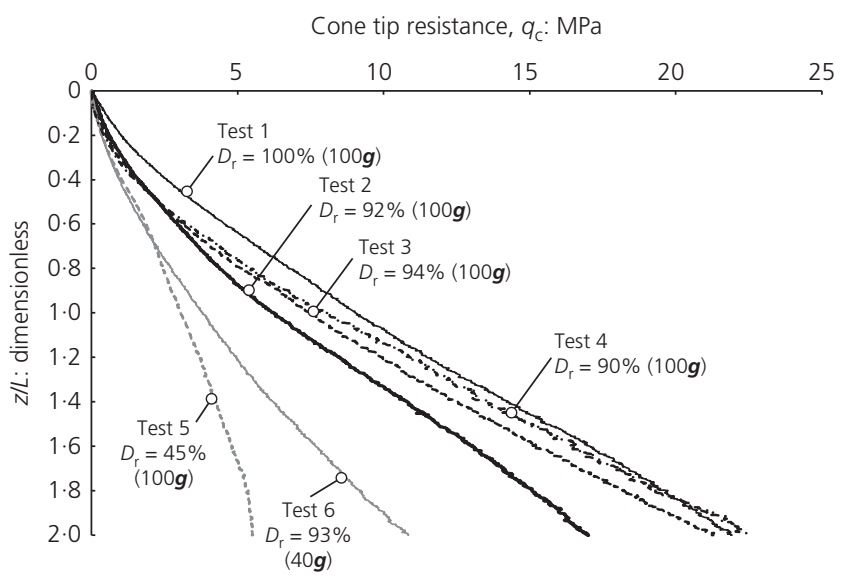

Figure 3. CPT profiles of the samples tested

where the difference in $q_{\mathrm{c}}$ is slight for samples at the same centrifuge acceleration and similar relative density. A single suction bucket test was performed in each sample. The temperature in the centrifuge chamber was monitored throughout for any changes to the pore fluid viscosity, which was confirmed to be negligible for all tests.

\subsection{Testing procedure}

In test 4 , the bucket was fully jacked into the sample to a final penetration depth $z_{\mathrm{fin}} / L=0.68$ (when the seals on the skirts started to peel due to high tip resistance) at a rate of $0.057 \mathrm{~mm} / \mathrm{s}$. This enabled comparison of fully jacked against suction-assisted installation. Each of the remaining tests involved an initial self-weight installation, achieved by penetration of the bucket in displacement control mode (i.e. jacked), during which the valve on the bucket lid was set such that the fluid within the bucket could drain to the free fluid above the bucket. Since the main goal was to study the following suction-assisted phase, a self-weight embedment of $10 \mathrm{~mm}$ was adopted across the tests, which yielded a normalised penetration $z_{\mathrm{s}-\mathrm{w}} / L=0 \cdot 2$, and allowed comparisons across the tests to be drawn. A constant penetration rate of $0.057 \mathrm{~mm} / \mathrm{s}$ was inferred from Bienen et al.
(2018), where a rigorous, load-controlled self-weight installation was adopted.

Once the target self-weight embedment was achieved, the actuator was switched to load control and the achieved vertical load, $V_{\text {s-w }}$ was kept constant during the following suctionassisted stage. Before actuating the syringe pump, the valve on the bucket lid was set to hydraulically connect the suction bucket to the syringe pump. The pump was operated at a constant pumping flow rate (Table 2), with a medium rate of $117.81 \mathrm{~mm}^{3} / \mathrm{s}$ (model scale) aiming for an initial bucket penetration rate $\dot{z}=0 \cdot 14 \mathrm{~mm} / \mathrm{s}$. The pumping flow rate was varied to $76.6 \mathrm{~mm}^{3} / \mathrm{s}$ (low) and $1178.1 \mathrm{~mm}^{3} / \mathrm{s}$ (high) to investigate the effects on soil displacement and changes in soil state. As discussed in Bienen et al. (2018), the penetration rate at model scale with the pore fluid viscosity matching the centrifugal acceleration corresponds to that in the prototype with water as a pore fluid, such that the overall installation duration is realistic.

Penetration tests of the bucket model in free fluid, against and away from the window, allowed the model-window friction contribution to be quantified as $\sim 5.5 \%$ of the vertical load measured in the jacked installation (test 4 ) at the final penetration depth $z_{\mathrm{fin}} / L=0 \cdot 68$. To overcome this increase in penetration resistance, negligible additional suction would be required $\left(4.5 \%\right.$ for $D_{\mathrm{m}}=50 \mathrm{~mm}$ at $100 \mathrm{~g}$ in dense sand, based on predictions using the Houlsby and Byrne (2005b) method).

All of the aforementioned steps were undertaken while the centrifuge was spinning at the target acceleration.

\subsection{PIV post-analysis}

The PIV results presented in the following sections analysed images from the high-resolution 'micro' camera of a bucket penetration of $\Delta z_{\mathrm{PIV}}=1 \mathrm{~mm}$ at different normalised depths $z_{\mathrm{PIV}} / L$. The measured displacement fields were normalised by $\Delta z_{\text {PIV }}$ for the generation of the resultant normalised displacement contour plots. The field of view of the 'micro' camera covered an area measuring approximately $80 \times 65 \mathrm{~mm}$ $(\sim 2500 \times 2000$ pixels $)$. 


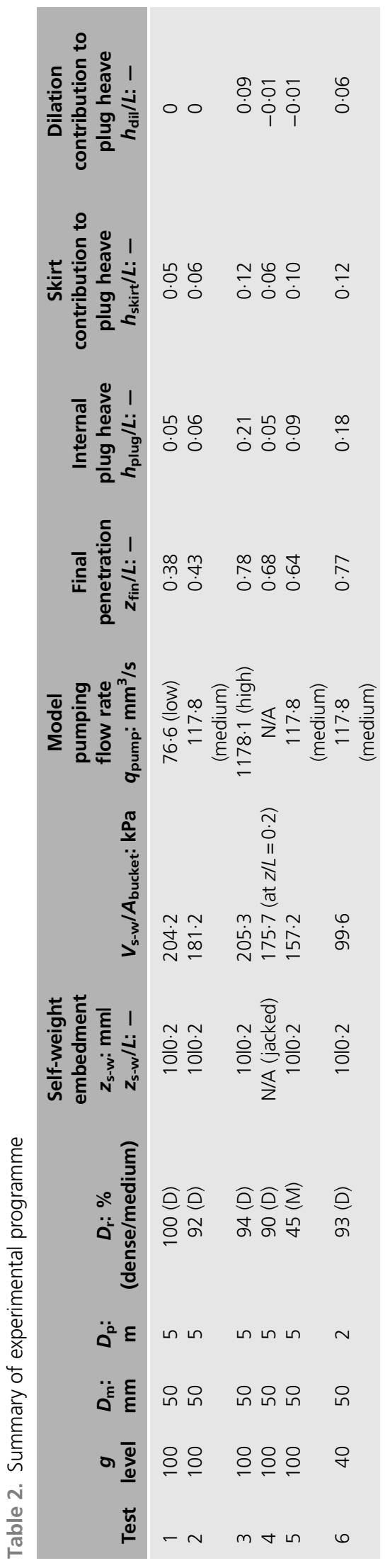

PIV analyses were performed using GeoPIV-RG (Stanier et al., 2015; Stanier and White, 2013), which incorporates a firstorder subset shape function, bi-quintic b-spline image intensity interpolation and an inverse compositional Gauss-Newton (ICGN) solution algorithm. The module relies on an array of subsets to analyse the soil domain, with the subset size and spacing of the subsets defined by the user. A subset size of 50 pixels was adopted here, equally spaced every 25 pixels (i.e. with a maximal initial subset overlap of 25 pixels). A variation of either the subset size (25 pixels, with spacing of 25 ) or the subset spacing (10 and 50 pixels, with subset size of 50) resulted in negligible changes to the observations, thus proving that the conclusions generated by interpreting the PIV measurements were insensitive to the PIV analysis parameters.

The automatic reference image updating scheme described in Stanier et al. (2015) was utilised to track the soil displacements throughout the whole image series automatically, while ensuring maximal correlations with the adoption of stringent convergence criteria. The recommended initial value of 0.75 for minimum correlation coefficient tolerance was trialled for all analyses (where $0=$ no correlation and $1=$ perfect correlation). In general, modern image-based deformation algorithms can tolerate relatively large deformations, so long as the deformations are not overly localised (Stanier et al., 2016). In this work occasional problems occurred in the upper part of the sand plug due to localised piping, where the minimum correlation coefficient $\left(\mathrm{CC}_{\mathrm{ZNCC}}\right)$ for a given image pair was less than the default criteria for GeoPIV-RG recommended by Stanier et al. (2015) of 0.75. Where these problems occurred, the analyses were concluded by relaxing the correlation coefficient criteria from the recommended values (from $\mathrm{CC}_{\mathrm{ZNCC}}=0.75$ to $0 \cdot 1<\mathrm{CC}_{\mathrm{ZNCC}}<0 \cdot 75$ ), before manually filtering all subsets from the analyses with a correlation coefficient equal to $0 \cdot 75$. In this way the validity of the measurements is ensured at the same time as allowing completion of the analysis in the event of localised piping occurring. This typically resulted in an automated deletion of $\sim 2-3 \%$ of the subsets analysed in highly localised zones of the sand plug.

\section{Results and discussion}

This section reports the interpretation of the results obtained through PIV analyses. Initial attention is dedicated to the development of the deformation mechanisms underlying both the self-weight and suction-assisted bucket installation phases. The effects of parameters such as stress level, relative density and pumping flow rate are illustrated. This is followed by examination of the changes in the soil state, experienced during installation, underpinned by analyses of volumetric and shear strain contours. Finally, the formation and development of the internal soil plug heave is analysed. 
International Journal of Physical Modelling in Geotechnics Volume 20 Issue 3
Observations during suction bucket installation in sand

Ragni, Bienen, Stanier, O'Loughlin and Cassidy

\subsection{Deformation mechanisms}

\subsubsection{Initial self-weight installation}

\subsubsection{EVOLUTION OF SOIL FAILURE MECHANISM WITH SKIRT PENETRATION DEPTH}

Figure 4 shows the evolution of the deformation mechanism during self-weight (jacked) installation of the bucket with $D_{\mathrm{p}}=5 \mathrm{~m}$ (test 4 ), at $z_{\mathrm{PIV}} / D=z_{\mathrm{PIV}} / L=0 \cdot 15,0 \cdot 30,0 \cdot 45$ and $0 \cdot 60$ (or $z_{\mathrm{PIV}} / t=3 \cdot 75,7 \cdot 5,11.25$ and 15 ). The dashed-dotted lines represent the lateral limits of the micro-camera field view, and not the rigid side of the strongbox.

The normalised resultant displacement contours reveal independent mechanisms around the skirt tips in the early stage of penetration (Figure 4(a), $z_{\mathrm{PIV}} / L=0 \cdot 15 ; z_{\mathrm{PIV}} / t=3 \cdot 75$ ), which bears similarity to a penetrating strip footing or CPT; analogies also used in penetration prediction methods for suction buckets (Andersen et al., 2008; Houlsby and Byrne, 2005b; Senders and Randolph, 2009).

Figure 4(b) shows that at $z_{\mathrm{PIV}} / L=0 \cdot 3\left(z_{\mathrm{PIV}} / t=7 \cdot 5\right)$ the two mechanisms interact in the interior of the suction bucket. The mechanism at the skirt tips transitions from a shallow failure mechanism that propagates to the surface both internally and externally to a quasi-deep mechanism comprised of tip resistance, external and internal skirt friction.

The increase in vertical stress generated by the penetrating skirts is thought to increase the skirt tip resistance to a greater extent in the interior of the suction bucket than the exterior, leading to an asymmetric change in effective stress. This down-drag enhancement cannot be neglected in a suction bucket installation prediction (Houlsby and Byrne, 2005b) Correspondingly, it can be seen in Figures 4(c) and 4(d) $\left(z_{\mathrm{PIV}} / L=0.45,0.60 ; z_{\mathrm{PIV}} / t=11.25,15\right.$, respectively $)$ that the deformation mechanism is asymmetric either side of the skirt, with most deformations occurring within the soil confined by the suction bucket skirt, whereas the deformation mechanism outside the bucket no longer extends to the soil surface. Accordingly, the mechanism can be already assumed fully localised around the skirt tips at $z_{\mathrm{PIV}} / t=11.25$ (Figure 4(c)). This is in broad agreement with the work of Bolton et al. (1999) on medium dense to dense sands, who found that the transition from shallow to deep behaviour for a CPT occurred at penetration depths of $\sim 10$ cone diameters, with the tip and frictional resistance components reflected in the penetration prediction methods from Houlsby and Byrne (2005b), Andersen et al. (2008) and Senders and Randolph (2009). It is finally noted in the PIV analyses that the soil contained by the skirt (the soil plug) is largely unaffected by the self-weight installation (Figure 4(d)), as the minimal plug heave observed confirms negligible changes in volume.

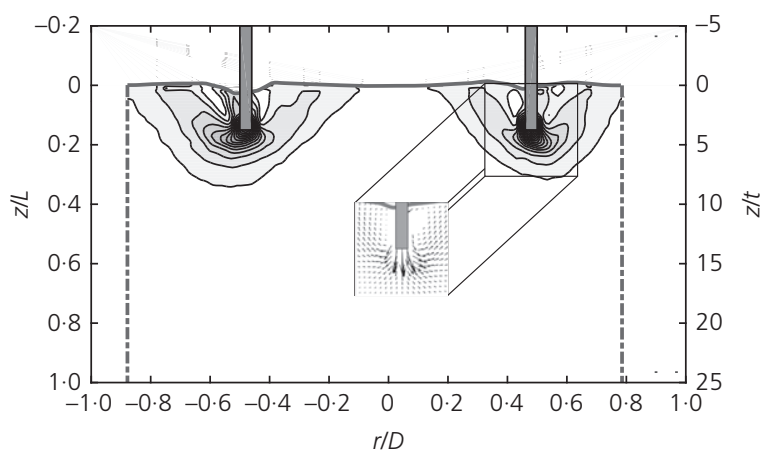

(a)

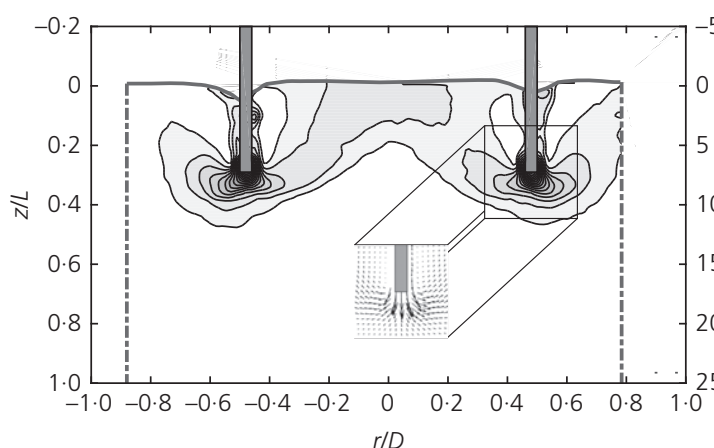

(b)

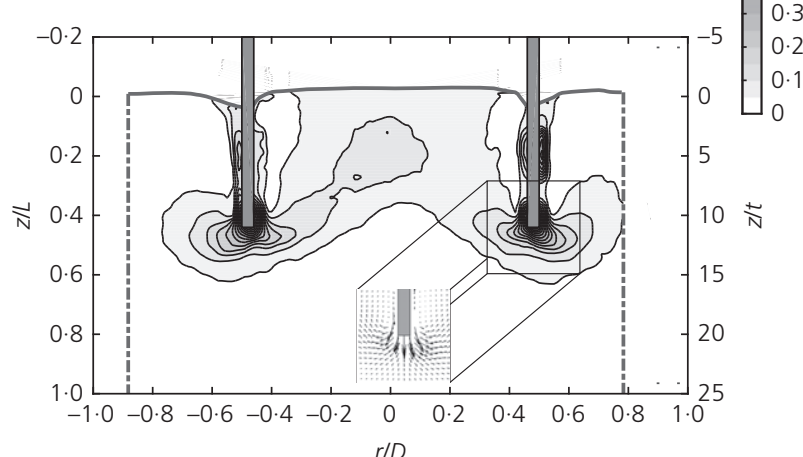

(c)

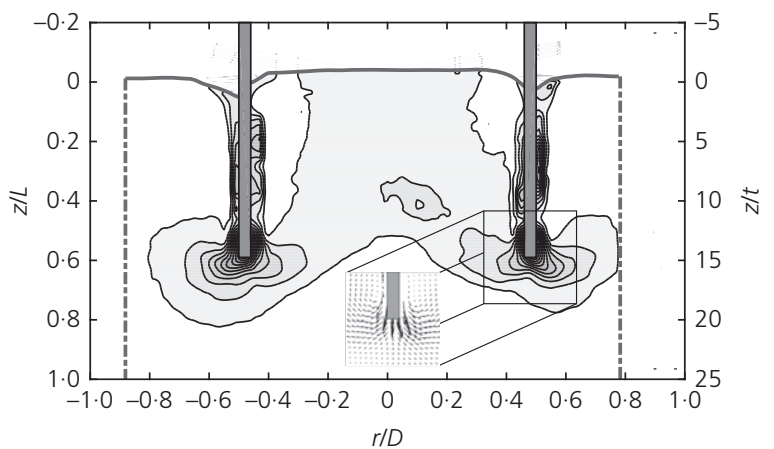

(d)

Figure 4. Normalised resultant displacement contours during selfweight installation for test 4 at increasing normalised depth $Z_{\mathrm{PIV}} / \mathrm{L}=0.15(\mathrm{a}) ; 0.30$ (b); 0.45 (c); 0.60 (d) 
International Journal of Physical Modelling in Geotechnics Volume 20 Issue 3
Observations during suction bucket installation in sand

Ragni, Bienen, Stanier, O'Loughlin and Cassidy

\subsubsection{EFFECTS OF STRESS LEVEL AND RELATIVE DENSITY}

Figure 5 examines the effect of different soil stress levels on the deformation mechanism, by comparing the self-weight penetration at $z_{\mathrm{PIV}} / L=0.1$ for test $6\left(N=40, D_{\mathrm{p}}=2 \mathrm{~m}\right.$, Figure 5(a)) and test $4\left(N=100, D_{\mathrm{p}}=5 \mathrm{~m}\right.$, Figure 5(b)). As expected, a reduction of the effective stresses under the skirt tips (test $6, N=40$ ) resulted in two separate tip mechanisms in the early stage of penetration, as already observed for test 4 $(N=100)$. The influence of a reduced stress level, however, is apparent in the resistance encountered at the end of the selfweight embedment $z_{\mathrm{s}-\mathrm{w}} / L=0 \cdot 2$. For test 6 at $N=40$ the load $V_{\text {s-w }}$ was $\sim 43 \%$ lower than for test 4 at $N=100$ at the same depth (compared with a theoretical reduction of $\sim 49 \%$, using the Houlsby and Byrne (2005b) method to estimate the contributions of the tip resistance, and the friction on the outside and inside of the skirt).

Similar conclusions can be drawn from test 5 in medium dense sand $\left(D_{\mathrm{r}} \sim 45 \%\right.$ at $\left.N=100\right)$. In terms of deformation mechanism, a response similar to that shown in Figure 5(b) was observed (Figure 6), implying that the relative density

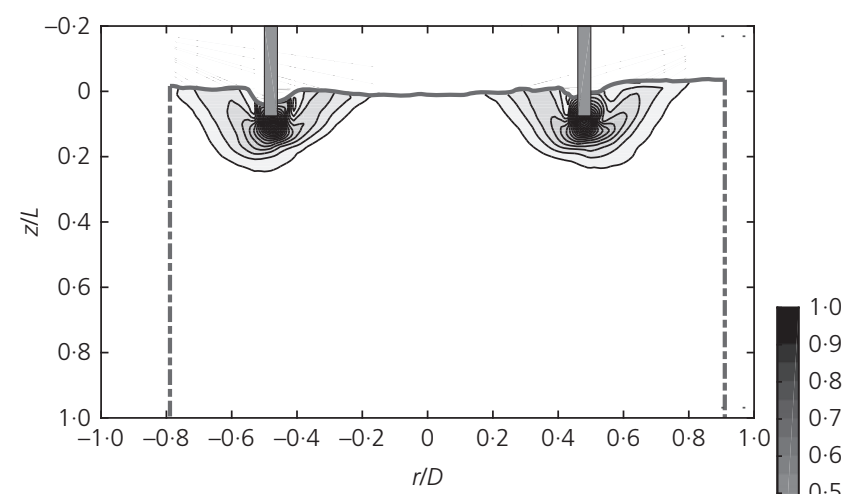

(a)

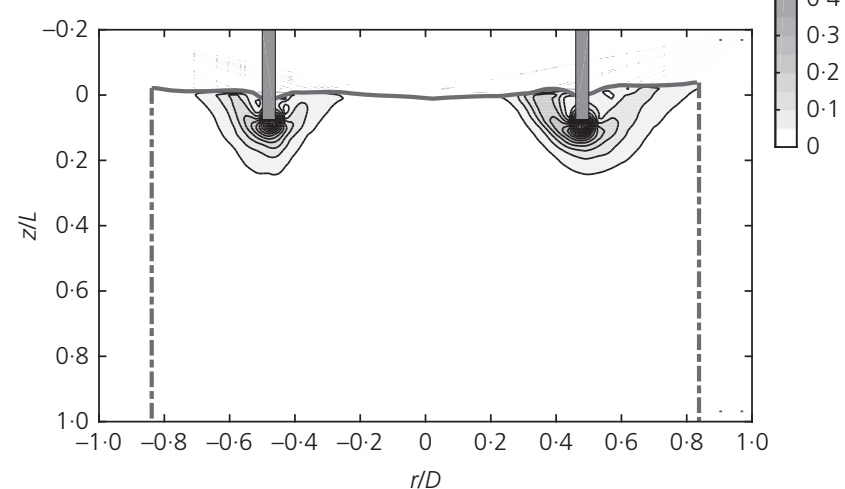

(b)

Figure 5. Normalised resultant displacement contours during self-weight installation at $Z_{\mathrm{PIV}} / L=0.1$ for test $6(\mathrm{a}=40 \mathrm{~g}$, $\left.D_{\mathrm{p}}=2 \mathrm{~m}\right)(\mathrm{a})$; and test $4\left(\mathrm{a}=100 \mathrm{~g}, D_{\mathrm{p}}=5 \mathrm{~m}\right)(\mathrm{b})$

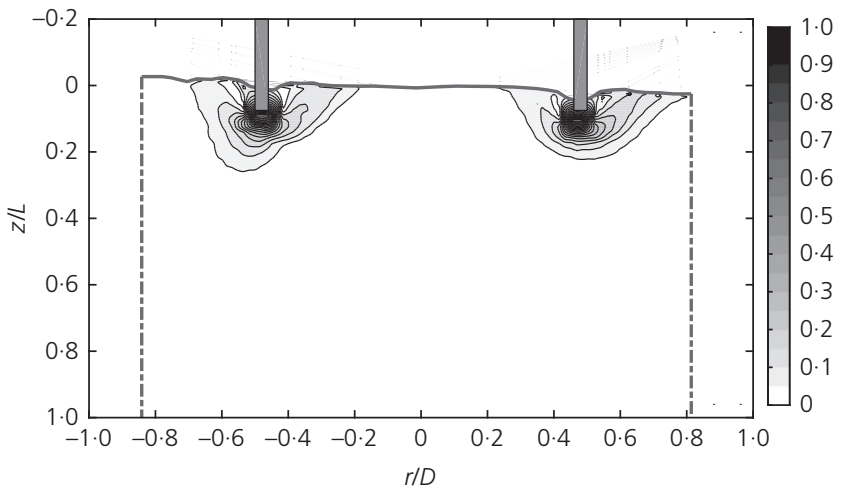

Figure 6. Normalised resultant displacement contours during self-weight installation at $z_{\text {PIV }} / L=0.1$ for $D_{\mathrm{r}} \sim 45 \%$ and $D_{\mathrm{p}}=5 \mathrm{~m}$ (test 5)

of the soil has little influence on the form of mechanism generated during self-weight (jacked) penetration. The reduction of relative density in test $5\left(D_{\mathrm{r}} \sim 45 \%\right)$ led to a $\sim 11 \%$ decrease in $V_{\mathrm{s}-\mathrm{w}}$ when compared with test 4 at a higher relative density $\left(D_{\mathrm{r}}=90 \%\right)$ at the same depth $z_{\mathrm{s}-\mathrm{w}} / L=0 \cdot 2$ (against a theoretical reduction of $\sim 21 \%$ predicted by the Houlsby and Byrne (2005b) method).

\subsubsection{Suction-assisted installation}

\subsubsection{EVOLUTION OF SOIL DEFORMATION MECHANISM WITH SKIRT PENETRATION DEPTH}

Figure 7 shows how the deformation mechanism evolves (due to suction installation) with penetration depth for $D_{\mathrm{p}}=2 \mathrm{~m}$ (test 6 ) at $z_{\mathrm{PIV}} / L=0 \cdot 28,0 \cdot 51$ and $0 \cdot 74$. As the bucket advances, the shape of the mechanism - an inverted ' $V$ ' similar in shape and slope to the self-weight installation phase (Figure 4(d)) remains largely the same; it simply migrates downwards with the penetrating bucket. However, compared with the selfweight phase, the mechanism is asymmetric about the skirt tip, with a bias towards soil flow to the bucket interior. The induced seepage flow reduces the effective stresses and generates steep displacement field gradients around the skirt tips. Consequently, the soil is displaced predominantly inside the bucket and upwards, which further facilitates installation.

\subsubsection{EFFECTS OF STRESS LEVEL AND RELATIVE DENSITY}

Figure 8 shows the effect of a variation in soil stress level $\left(N=40, D_{\mathrm{p}}=2 \mathrm{~m}\right.$ in Figure $8(\mathrm{a})$, and $N=100, D_{\mathrm{p}}=5 \mathrm{~m}$ in Figure $8(\mathrm{~b})$ ) on the normalised resultant displacement contour plots during suction-assisted penetration at $z_{\mathrm{PIV}} / L=0 \cdot 28$. This links to the study of the stress level effect during self-weight penetration in Figure 5. A similar deformation mechanism is observed for the two cases, where the soil under the skirt tips is quickly displaced, following a prevalent inwards motion. 
Observations during suction bucket installation in sand

Ragni, Bienen, Stanier, O'Loughlin and Cassidy

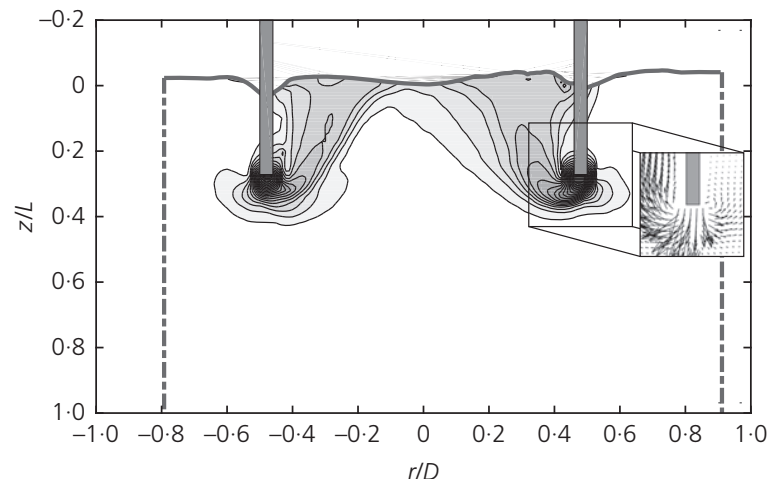

(a)

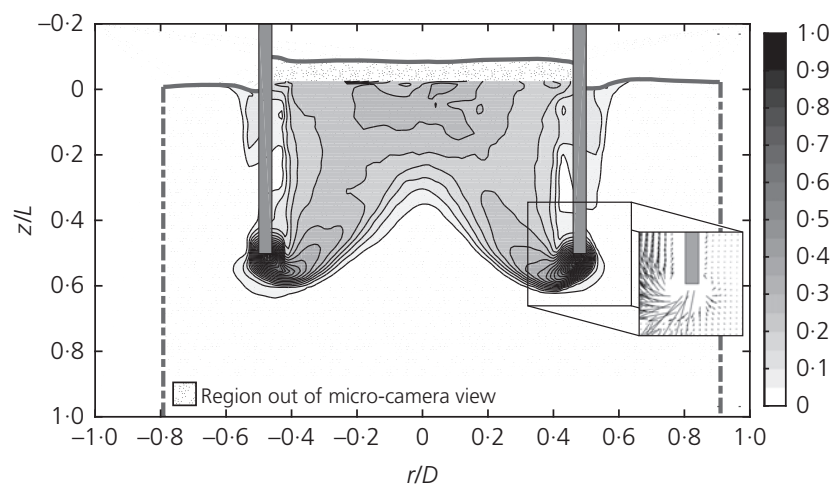

(b)

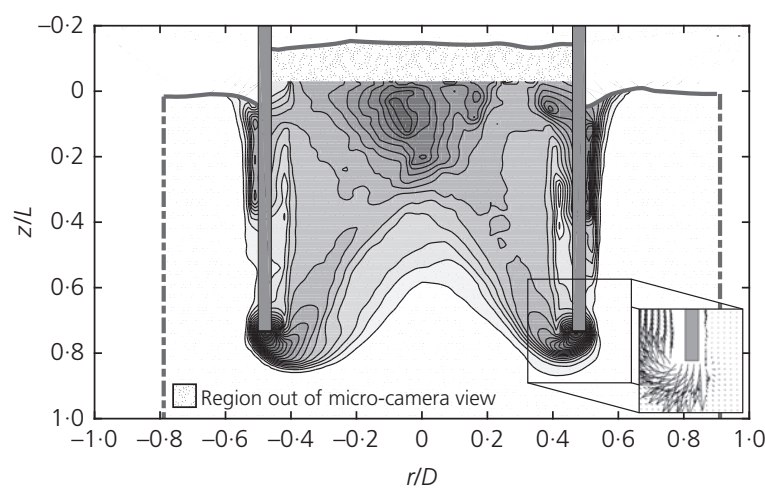

(c)

Figure 7. Normalised resultant displacement contours during suction-assisted installation for $N=40$, and $D_{p}=2 \mathrm{~m}$ (test 6) at $Z_{\text {PIV }} / L=0.28(\mathrm{a}) ; 0.51(\mathrm{~b}) ; 0.74$ (c)

This is indicative of effective stresses under the skirt tips being reduced as a result of the applied suction. The mechanisms emanating from either skirt have merged to an inverted ' $\mathrm{V}$ '. The case with reduced stress level, $N=40\left(D_{\mathrm{p}}=2 \mathrm{~m}\right.$, test 6$)$ was installed to a final penetration, $z_{\mathrm{fin}} / L=0 \cdot 77$, whereas only $z_{\text {fin }} / L=0.43$ was achieved for test 2 at $N=100\left(D_{\mathrm{p}}=5 \mathrm{~m}\right)$, having applied a constant medium pumping flow rate, $q_{\text {pump }}=117 \cdot 8 \mathrm{~mm}^{3} / \mathrm{s}$ (model scale) in both tests. This is mainly

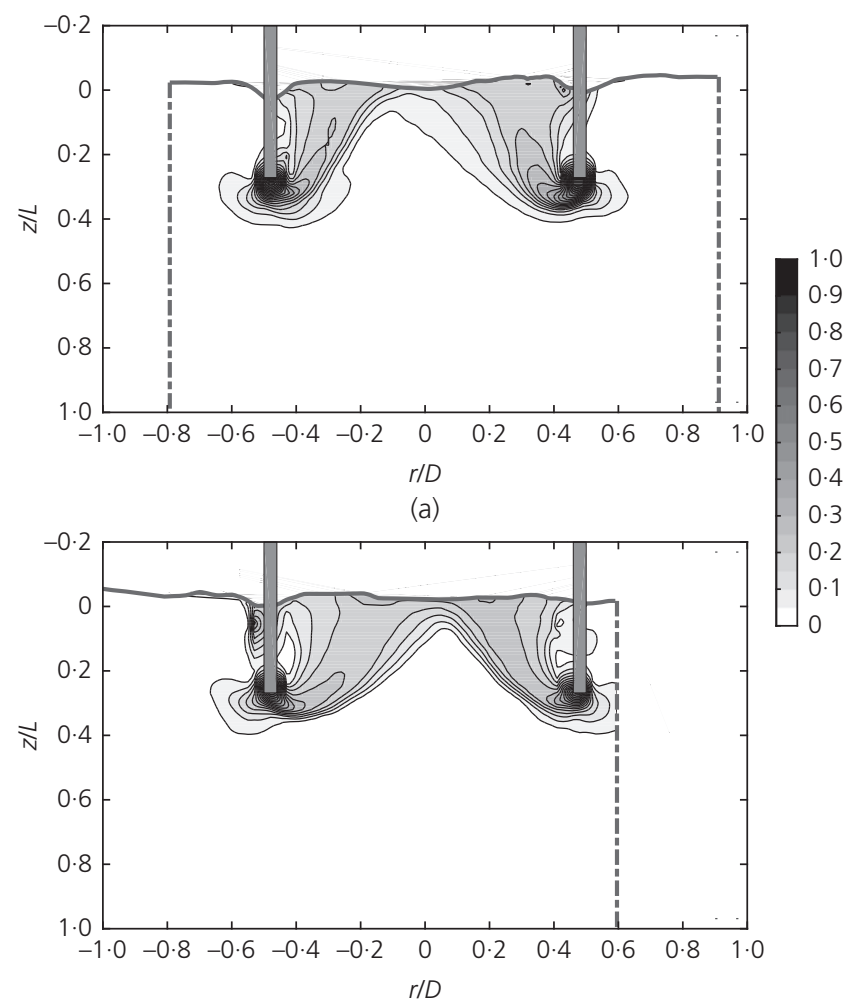

(b)

Figure 8. Normalised resultant displacement contours during suction-assisted installation at $Z_{\mathrm{PIV}} / L=0.28$ for test $6(N=40$, $\left.D_{\mathrm{p}}=2 \mathrm{~m}\right)(\mathrm{a})$; and test $2\left(N=100, D_{\mathrm{p}}=5 \mathrm{~m}\right)(\mathrm{b})$

due to the lower effective stress in the soil under the skirt tips in test $6\left(N=40, D_{\mathrm{p}}=2 \mathrm{~m}\right)$. Although suction-induced seepage is responsible for reducing the effective stresses around the skirt tips (and thus the tip resistance) to extremely low values when critical hydraulic gradients are approached, the difference in the initial effective stresses at the skirt tips is reflected in the final penetrations achieved.

Relative density did not appear to influence the shape of the mechanism (Figure 9), but did affect the final penetration depth achieved. The suction bucket reached a larger final depth of $z_{\text {fin }} / L=0.64$ in medium dense sand (test $5, D_{\mathrm{r}} \sim 45 \%$ ) compared with $z_{\text {fin }} / L=0.43$ achieved with the same pumping flow rate in the dense sample $\left(D_{\mathrm{r}}=92 \%\right.$, test 2$)$.

\subsubsection{EFFECT OF PUMPING FLOW RATE}

No significant changes in the deformation mechanism were observed when the pumping flow rate was increased by one order of magnitude (to $1178 \cdot 1 \mathrm{~mm}^{3} / \mathrm{s}$, test 3 , Figure 10), although the slope of the inverted ' $\mathrm{V}$ ' mechanism is slightly flattened for increased flow rate (Figure 10(c)) when compared 
International Journal of Physical Modelling in Geotechnics Volume 20 Issue 3
Observations during suction bucket installation in sand

Ragni, Bienen, Stanier, O'Loughlin and Cassidy

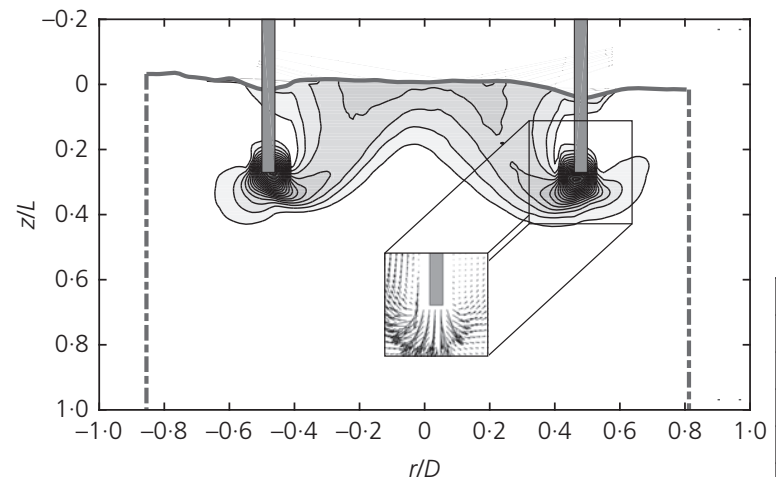

(a)

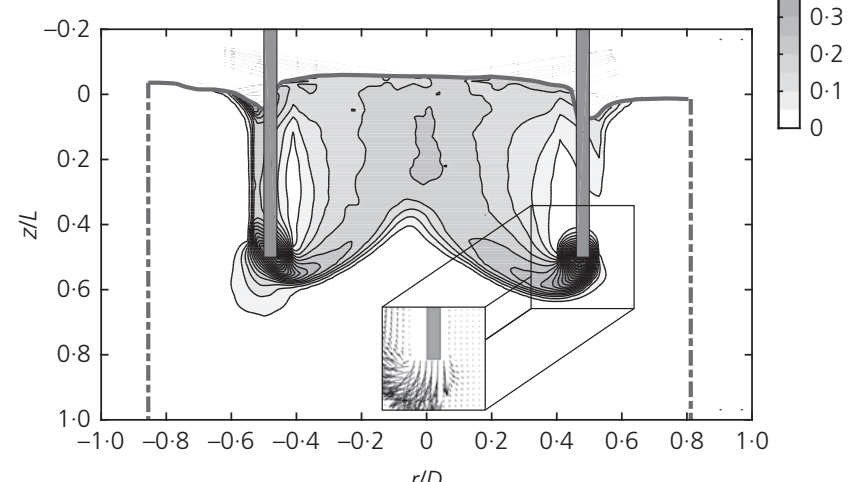

(b)

Figure 9. Normalised resultant displacement contours during suction-assisted installation for $D_{\mathrm{p}}=5 \mathrm{~m}$ and medium sand relative density $\left(D_{\mathrm{r}} \sim 45 \%\right.$, test 5$)$ at $Z_{\mathrm{PIV}} / L=0.28(\mathrm{a}) ; 0.51$ (b)

with the medium flow rate (Figures 7(c) and 9(b)). This is a result of the larger suction generated at the lid invert and hence larger seepage around the skirt tip and through the soil plug, which encourages a larger amount of soil to be displaced upwards.

The different pumping flow rates translate to different initial suction bucket penetration rates $\dot{z}$ (Figure 11). The increased pumping flow rate of $1178.1 \mathrm{~mm}^{3} / \mathrm{s}$ resulted in an initial $\dot{z}$ of approximately $0.8 \mathrm{~mm} / \mathrm{s}$. However, the curvature of the test result indicates more significant seepage losses when compared with the other tests (with a theoretical constant suction bucket penetration rate signifying no seepage losses), brought about by increasing permeability through loosening of the soil plug. This is consistent with full model tests (Bienen et al., 2018) and highlights that a fast-reducing volume pumped by the syringe is effectively translated to suction, with the remaining part dispersed in seepage losses, such that increased permeability and larger plug heave are expected. The variation in effective stresses due to the applied pumping flow rate affected the final installation depth: increased rates $(76 \cdot 6,117 \cdot 8$ and

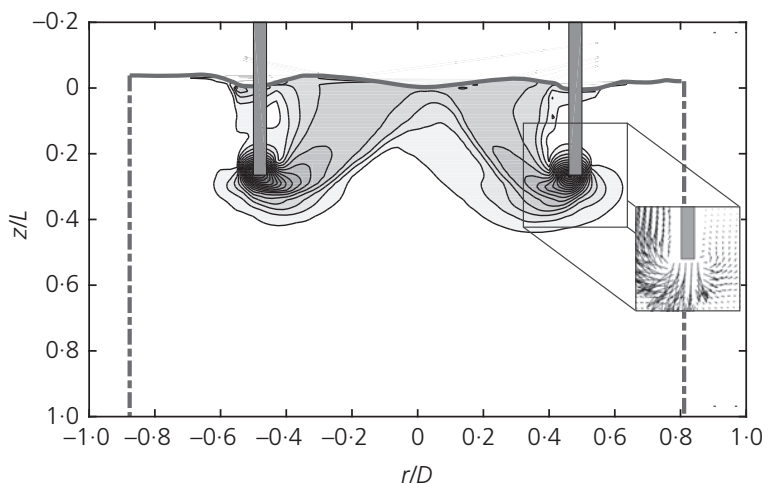

(a)

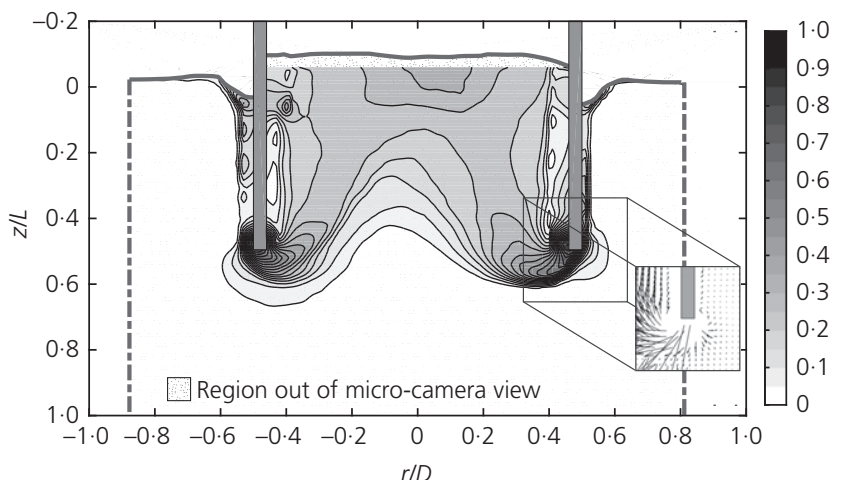

(b)

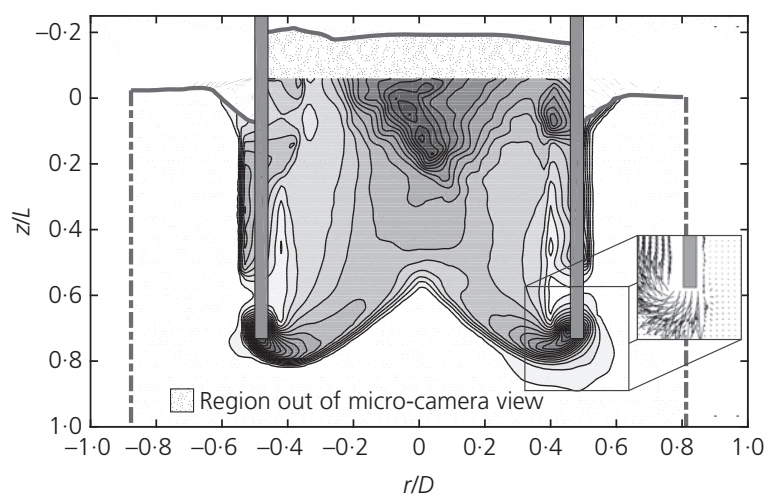

(c)

Figure 10. Normalised resultant displacement contours during suction-assisted installation for $D_{\mathrm{p}}=5 \mathrm{~m}$ and high pumping flow rate $\left(1178.1 \mathrm{~mm}^{3} / \mathrm{s}\right.$, test 3$)$ at $Z_{\mathrm{PIV}} / \mathrm{L}=0.28$ (a); 0.51 (b); 0.74 (c)

$1178 \cdot 1 \mathrm{~mm}^{3} / \mathrm{s}$ for tests 1,2 and 3 ) led to deeper penetration $\left(z_{\text {fin }} / L=0.38,0.43\right.$ and 0.78 , respectively) for the same suction bucket geometry. This agrees with findings from full model tests (Bienen et al., 2018).

\subsection{Changes in soil state}

The strains presented in each subfigure of the following sections were obtained over the same penetration, 


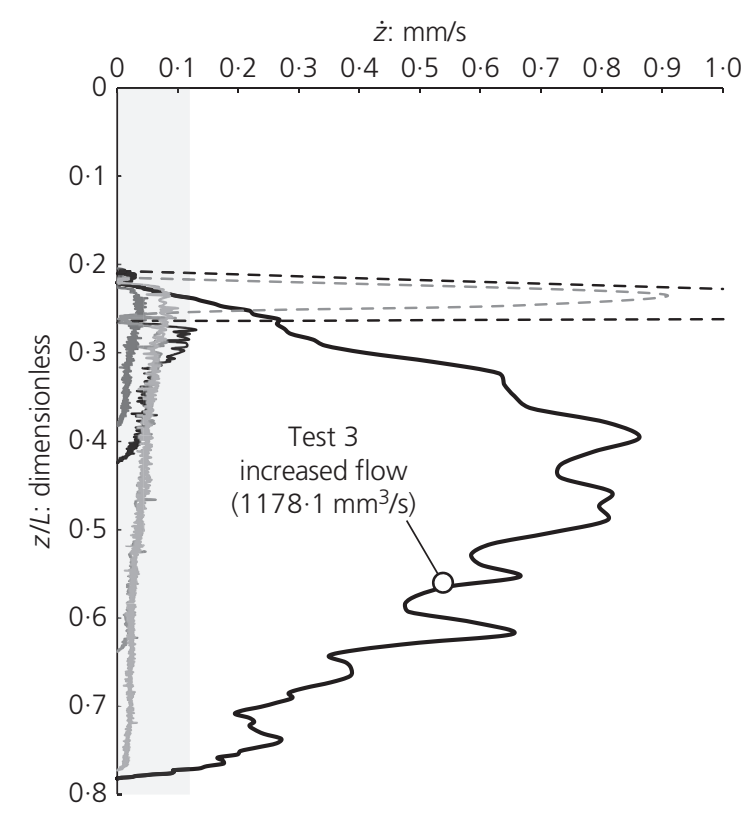

(a)

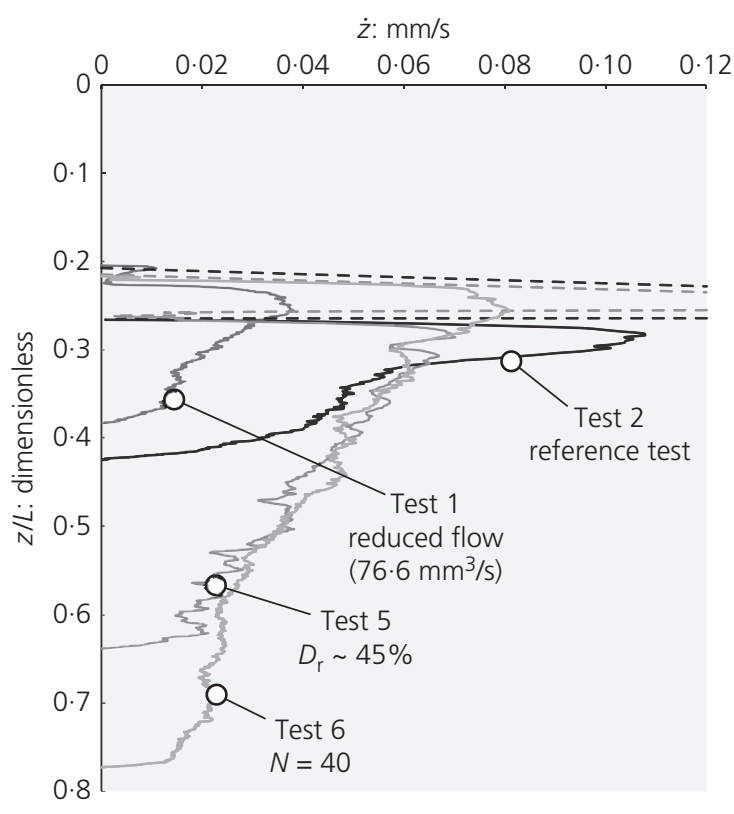

(b)

Figure 11. Vertical profiles of penetration rate $\dot{z}$ (a) for all tests, and (b) closed-in area (test 3 excluded). Note: (i) spikes in $\dot{z}$ represented with dashed lines are thought to be due to some minor air vacuum trapped in the syringe pipe; (ii) curves in Figure 10(b) averaged every ten points to improve clarity

$\Delta z_{\mathrm{PIV}}=1 \mathrm{~mm}$ used to calculate the normalised displacement contours

The dashed-dotted lines represent the lateral limits of the micro-camera field view, and not the rigid side of the strongbox. In the proximity of these lateral limits, some subplots (e.g. Figure 14(b)) may present minor artefacts (i.e. unrealistic strains) due to: (i) the camera lens-induced distortions being most significant at the periphery of the image and (ii) the lens distortion models typically used to make these corrections fitting the actual distortion least well in the periphery of the images.

\subsubsection{Initial self-weight installation}

Total shear strains, $\gamma_{\mathrm{s}}$ experienced during jacked penetration (test 4) are shown in Figure 12, at $z_{\mathrm{PIV}} / L=0 \cdot 15,0 \cdot 30,0 \cdot 45$ and $0 \cdot 60$. Deformations are concentrated around the tips and along the skirts. The generation of shear bands propagating from the skirt tips are clearly visible from $z_{\mathrm{PIV}} / L=0.3$ (Figure 12(b)). These bands interact in the shape of the inverted ' $\mathrm{V}$ ' already observed when discussing the deformation mechanism.

Figure 13 shows the volumetric strain, $\varepsilon_{\mathrm{V}}$ distribution for jacked penetration (negative values indicate extension; in a dense sample, $\varepsilon_{\mathrm{V}}=-10 \%$ would be responsible for the localised reduction of $D_{\mathrm{r}}$ from 100 to $45 \%$ ). As the bucket advances, the sand beneath the skirt tips experiences minor compression. Conversely, significant dilation is observed in the region immediately above the skirt tips, as expected. The elevated tip resistance associated with jacked installation (test 4) caused the hard rubber at the model/window interface to migrate upwards as the final penetration depth was reached. This caused a slight misalignment between the skirt tips and the localised volumetric expansion evident in Figures 13(c) and 13(d). Along the remainder of the skirts, some volumetric change is observed, although minor variations in the width of the soft sealant (sub $\mathrm{mm}$ ) may have influenced the volumetric strain magnitudes observed in these regions. The soil within the bucket does not experience any noticeable change in volume.

\subsubsection{Suction-assisted installation}

Figures 14 and 15 show the total shear $\left(\gamma_{\mathrm{s}}\right.$, Figure 14) and total volumetric $\left(\varepsilon_{\mathrm{v}}\right.$, Figure 15) strains resulting from the applied pumping flow rate of $1178.1 \mathrm{~mm}^{3} / \mathrm{s}$ (test 3 ) at depths $z_{\text {PIV }} / L=0 \cdot 28,0.51$ and $0 \cdot 74$. Similar observations in terms of strain distribution could be made for the test at a lower stress level (test 6 with $N=40$, and $D_{\mathrm{p}}=2 \mathrm{~m}$, see Figures 16 and 17). 


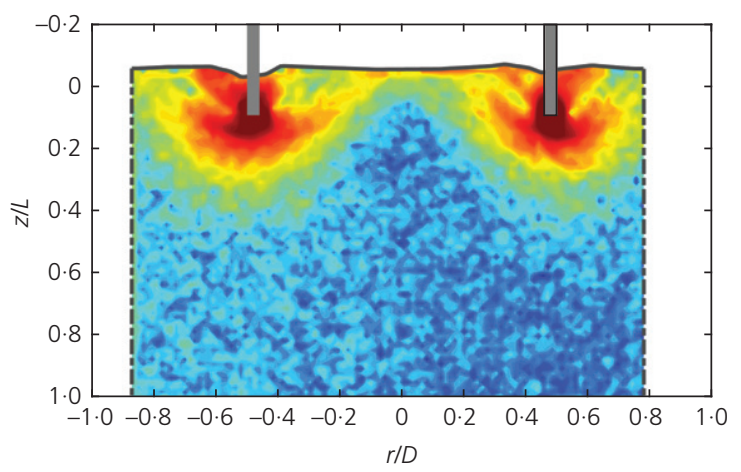

(a)

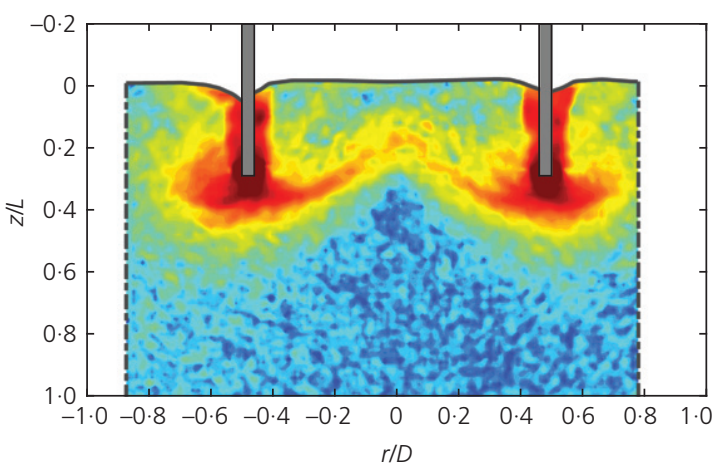

(b)

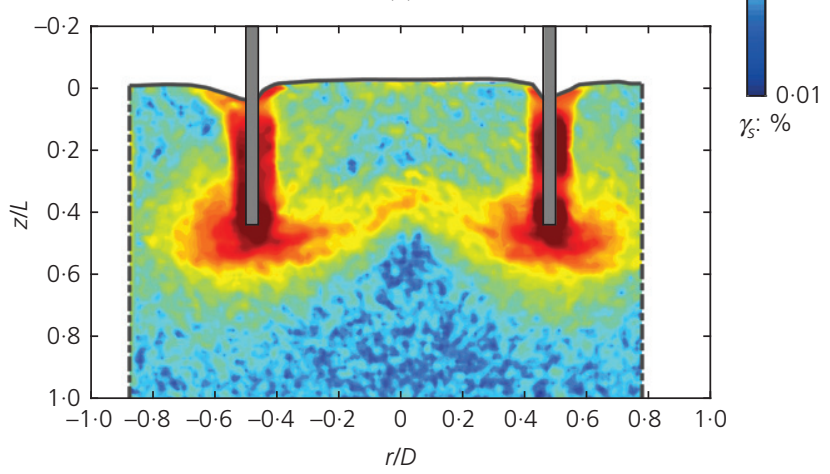

(c)

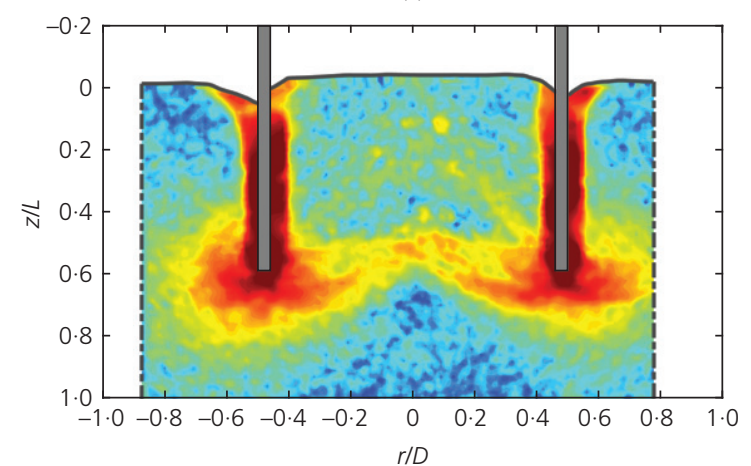

(d)

Figure 12. Total shear strain $\gamma_{\mathrm{s}}(\%)$ contours during self-weight installation for test 4 at increasing normalised depth $z_{\mathrm{PIV}} / L=0 \cdot 15$ (a); 0.30 (b); 0.45 (c); 0.60 (d)
Observations during suction bucket

installation in sand

Ragni, Bienen, Stanier, O'Loughlin and

Cassidy

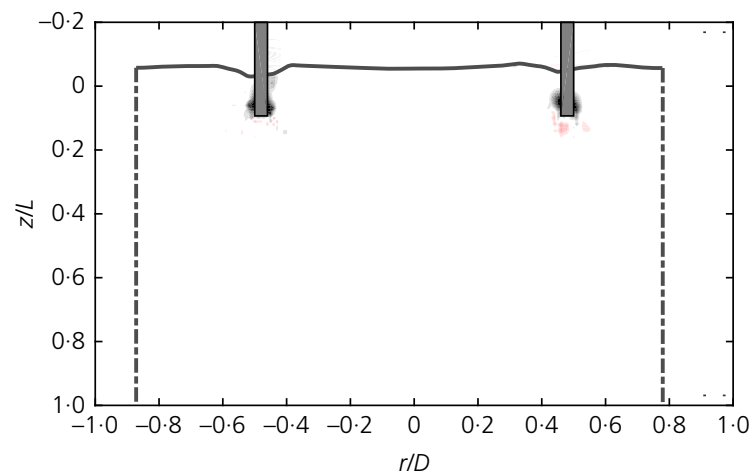

(a)

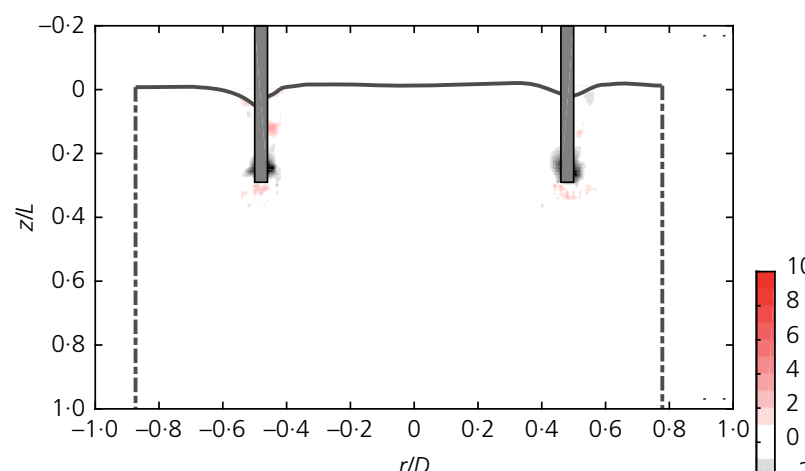

(b)

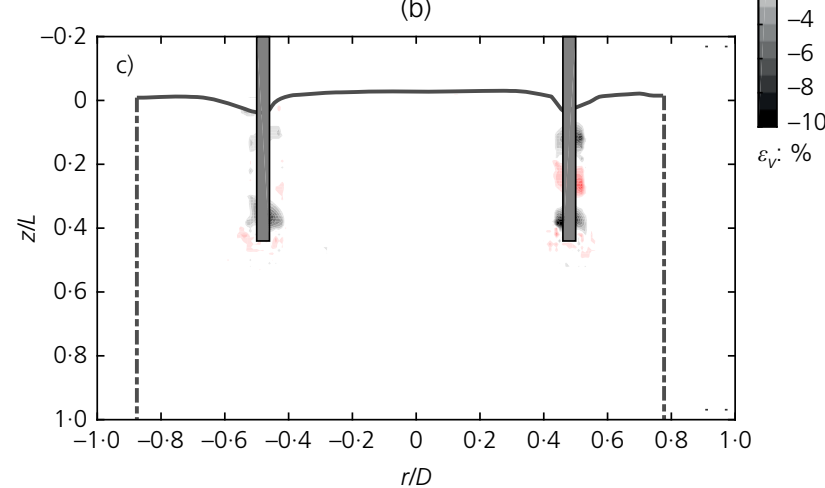

(c)

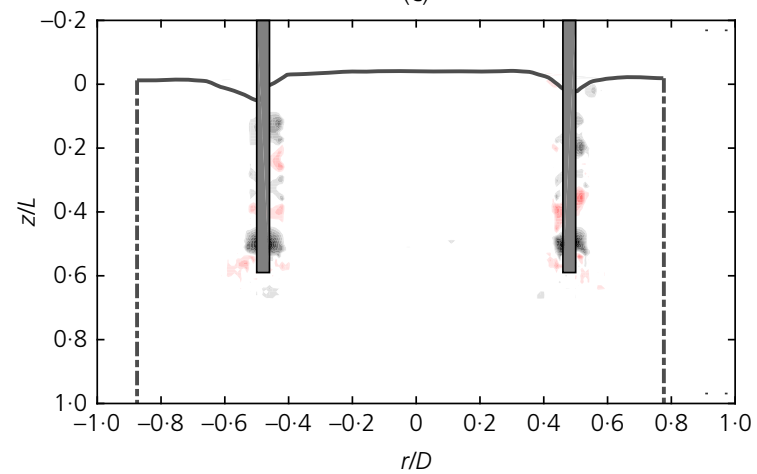

(d)

Figure 13. Total volumetric strain $\varepsilon_{\mathrm{v}}(\%)$ contours during selfweight installation for test 4 at increasing normalised depth $Z_{\mathrm{PIV}} / L=0.15$ (a); 0.30 (b); 0.45 (c); 0.60 (d) 
Observations during suction bucket

installation in sand

Ragni, Bienen, Stanier, O'Loughlin and Cassidy

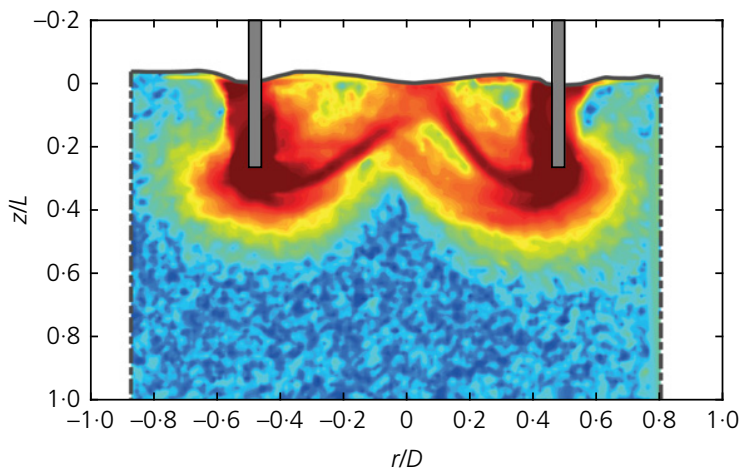

(a)

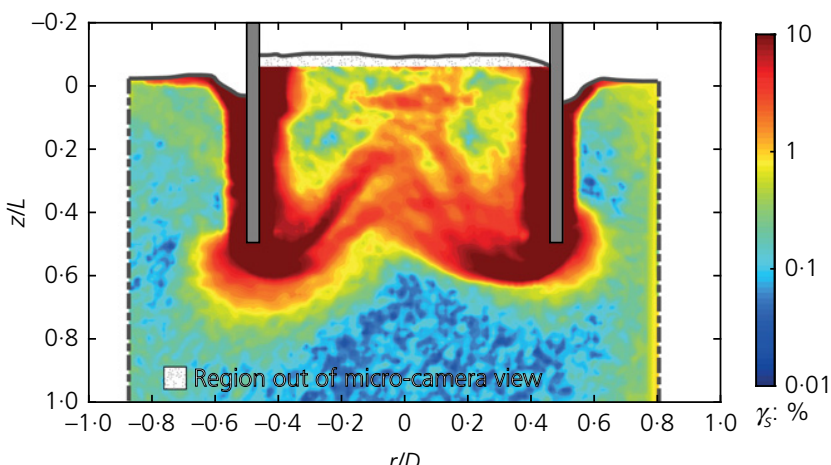

(b)

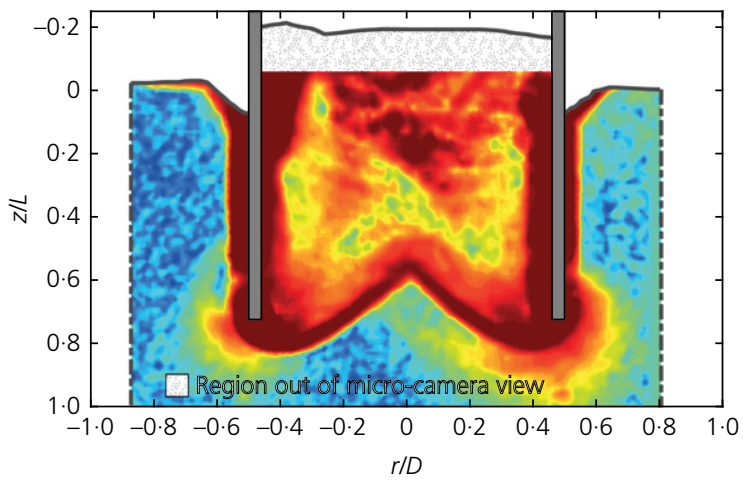

(c)

Figure 14. Total shear strain $\gamma_{s}(\%)$ contours during suctionassisted installation for $D_{\mathrm{p}}=5 \mathrm{~m}$ and high applied pumping flow rate $\left(1178.1 \mathrm{~mm}^{3} / \mathrm{s}\right.$, test 3$)$ at $Z_{\text {PIV }} / L=0.28(a) ; 0.51$ (b); 0.74 (c)

Figure 14 clearly highlights localised regions developing large shear strains. Friction is responsible for the shearing of the sand in contact with the bucket skirts. Regions of shearing are seen to develop towards the inside of the bucket. As penetration continues, shear strains at the bottom of the soil plug constantly increase (Figure 14(b)), until clearly defined shear bands in the characteristic inverted ' $\mathrm{V}$ ' shape, with asymmetry around the skirt tips, have developed fully (Figure 14(c)). This is in agreement with the observations

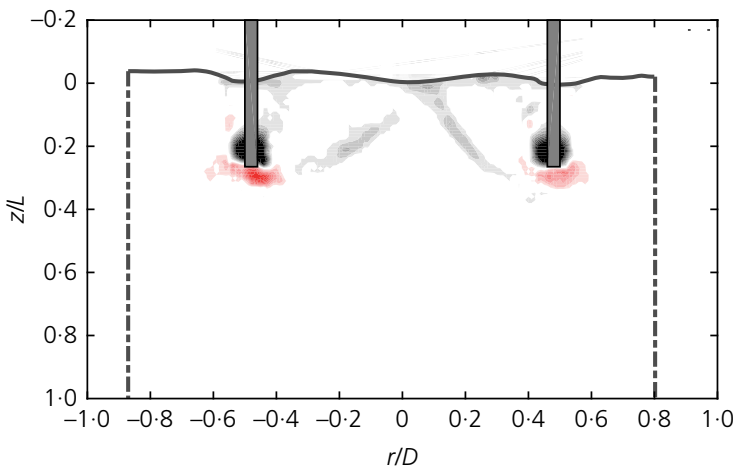

(a)

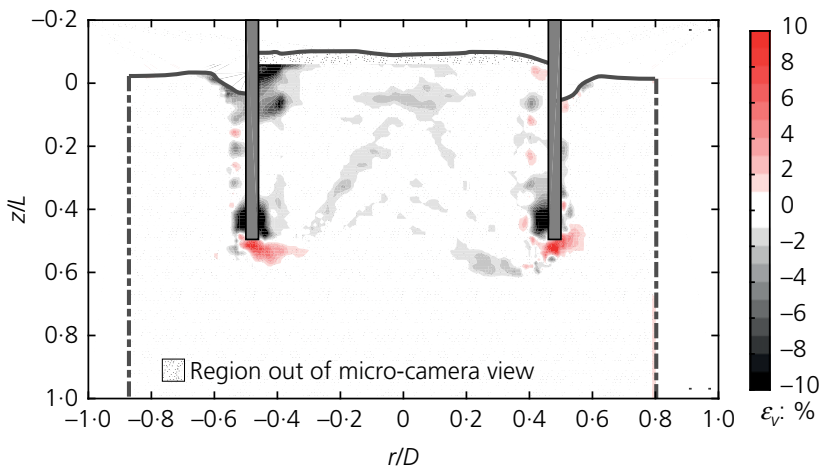

(b)

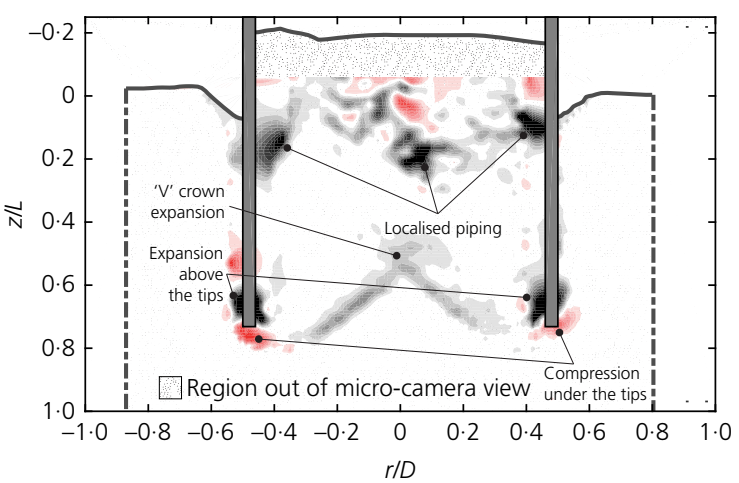

(c)

Figure 15. Total volumetric strain $\varepsilon_{\mathrm{v}}(\%)$ contours during suctionassisted installation for $D_{p}=5 \mathrm{~m}$ and high pumping flow rate $\left(1178.1 \mathrm{~mm}^{3} / \mathrm{s}\right.$, test 3$)$ at $Z_{\mathrm{PIV}} / L=0.28(\mathrm{a}) ; 0.51(\mathrm{~b}) ; 0.74(\mathrm{c})$

made for the suction-assisted deformation mechanism, where the application of suction preferentially causes the soil to flow into the bucket.

Volumetric expansion was consistently experienced above the tips and at the crown of the inverted ' $\mathrm{V}$ ' mechanism within the suction bucket plug (Figure 15), as well as where localised piping took place - that is, where the hydraulic gradients are thought to have reached critical values (Figure 15(c)). 


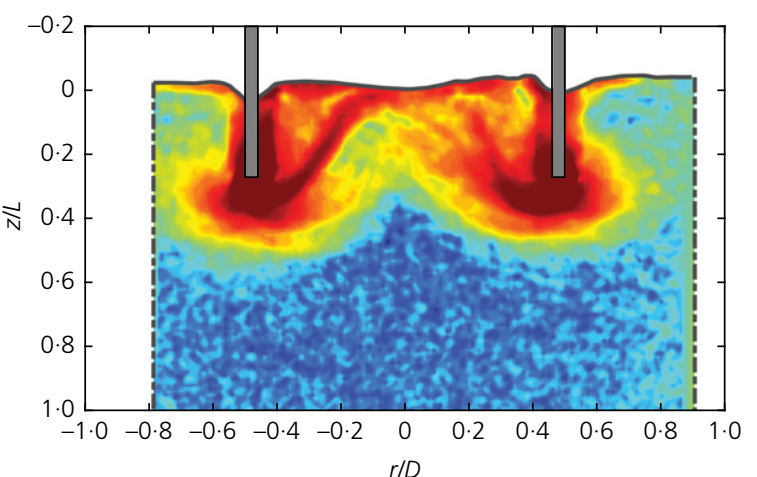

(a)

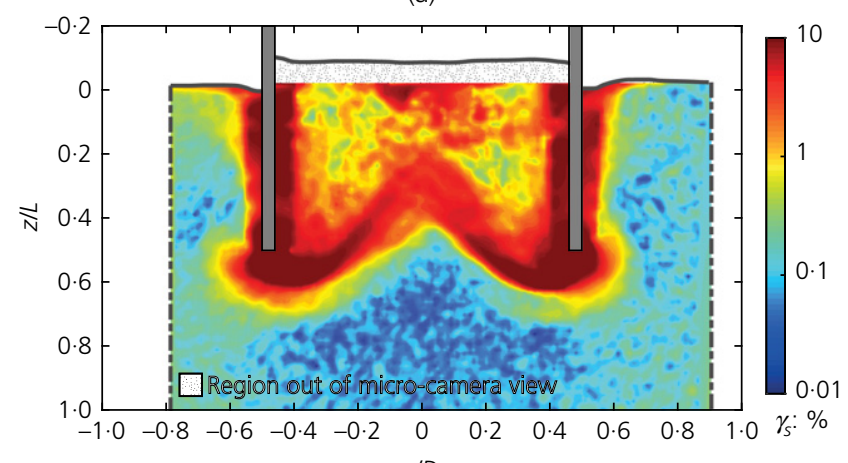

$r / D$

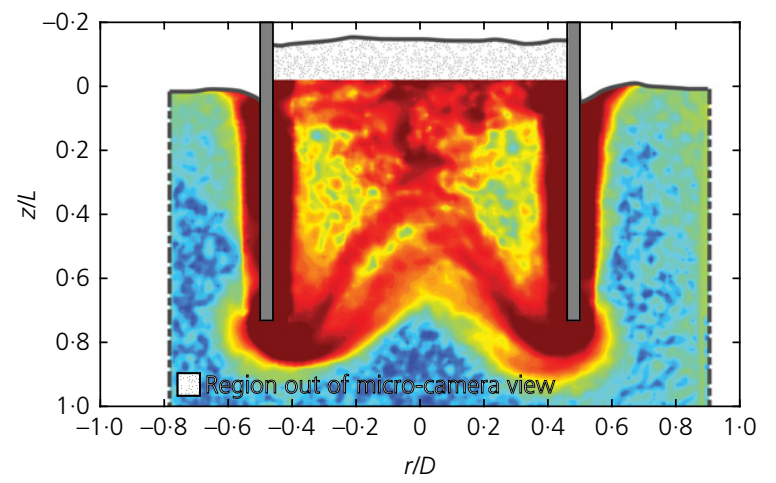

(c)

Figure 16. Total shear strain $\gamma_{s}(\%)$ contours during suctionassisted installation for $N=40$, and $D_{p}=2 \mathrm{~m}$ (test 6 ) at $Z_{\mathrm{PIV}} / L=0.28$ (a); 0.51 (b); 0.74 (c)

The rapid volumetric changes due to piping led to the deletion of several subsets during the PIV analyses (see Section 2.4), with the resulting output indicating variable contraction in the upper part of the soil plug (e.g. Figures 15(c), 17(b) and 17(c)), which is questionable. Shearing generated at the soil-skirt interface appears to be responsible only for minor expansion.

Test with reduced relative density, $D_{\mathrm{r}} \sim 45 \%$ (tests 5, Figures 18 and 19) showed comparable qualitative strain
Observations during suction bucket installation in sand

Ragni, Bienen, Stanier, O'Loughlin and Cassidy

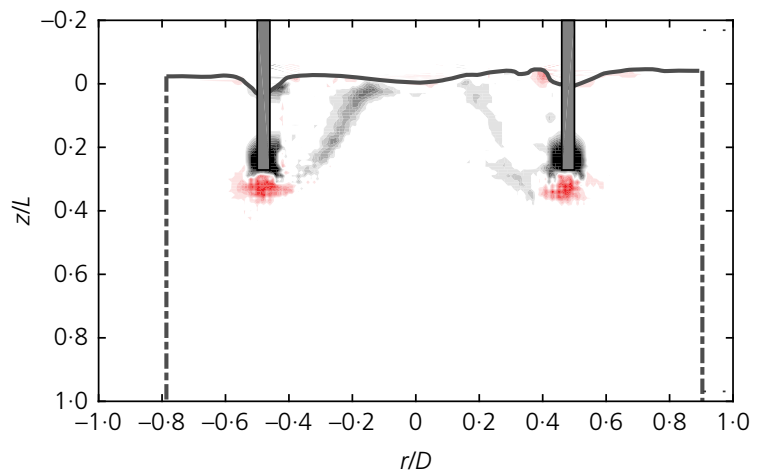

(a)

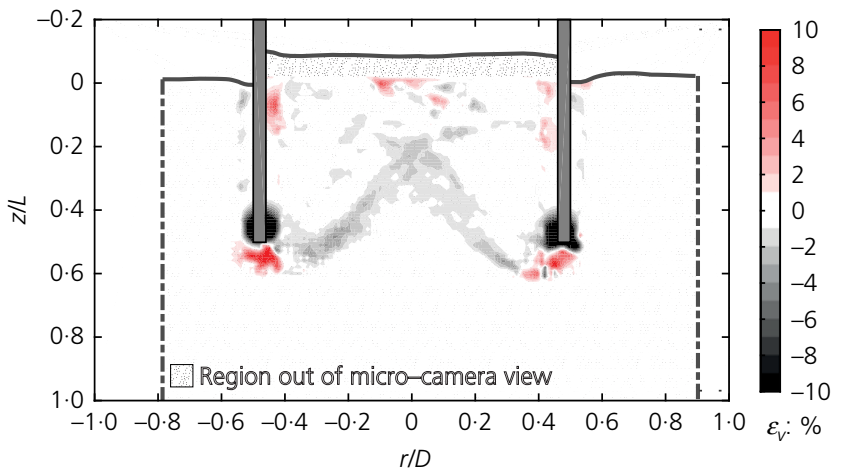

(b)

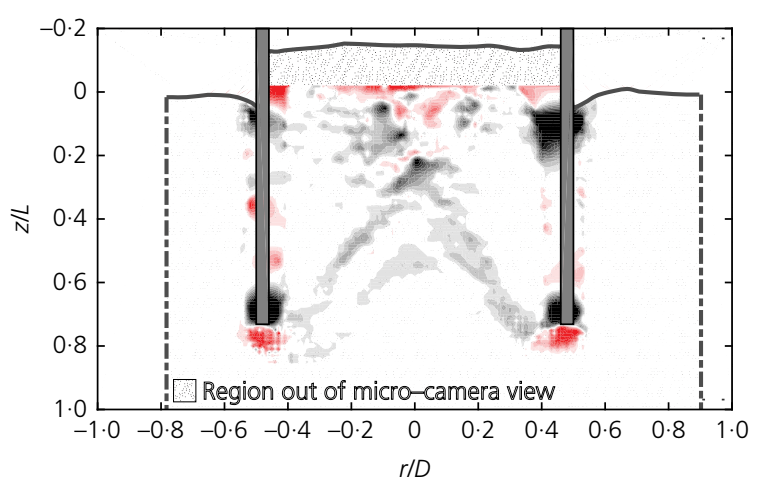

(c)

Figure 17. Total volumetric strain $\varepsilon_{\mathrm{v}}(\%)$ contours during suctionassisted installation for $N=40, D_{\mathrm{p}}=2 \mathrm{~m}$ (test 6 ) at $\mathrm{Z}_{\mathrm{PIV}} / \mathrm{L}=0.28$ (a) 0.51 (b); 0.74 (c)

distributions, although characterised by more pronounced compression under the skirt tips, and less dilation above the skirt tips and inside the bucket.

Since the inverted ' $V$ ' travels through the soil contained within the skirt as the penetration progresses, it is reasonable to assume that in dense sand - at some stage - the entire plug will undergo some dilation, which results in a reduction in relative density (increase in void ratio) and a related increase 
International Journal of Physical Modelling in Geotechnics Volume 20 issue 3
Observations during suction bucket

installation in sand

Ragni, Bienen, Stanier, O'Loughlin and

Cassidy

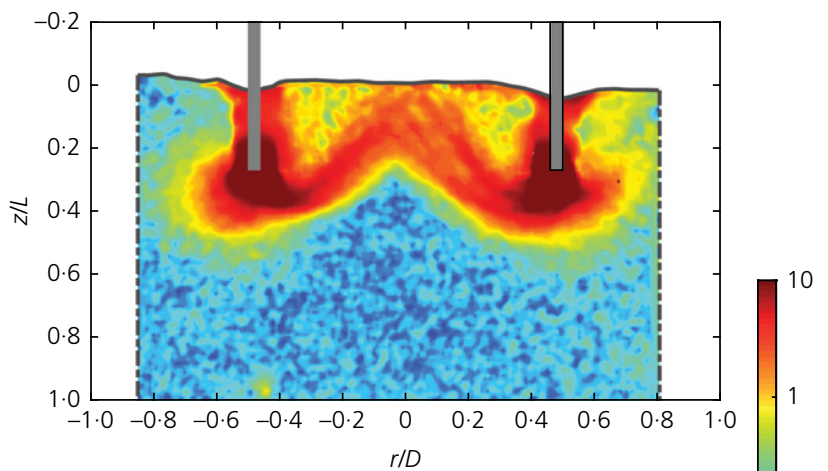

(a)

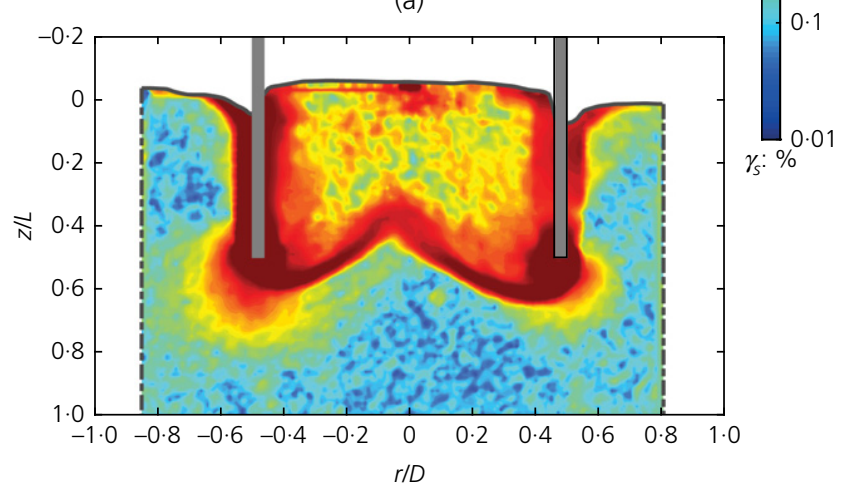

(b)

Figure 18. Total shear strain $\gamma_{\mathrm{s}}(\%)$ contours during suctionassisted installation for $D_{\mathrm{p}}=5 \mathrm{~m}$ and $D_{\mathrm{r}} \sim 45 \%$ (test 5 ) at $Z_{\text {PIV }} / L=0.28(a) ; 0.51$ (b)

in permeability, $k$. A comprehensive PIV analysis was carried out for test 3 , which achieved complete installation (i.e. full skirt penetration). The analysis of the soil within the bucket was based on the entire suction-assisted penetration stage $\left(\Delta z_{\text {PIV }}=28.5 \mathrm{~mm}\right)$, and yielded an average dilation, $\varepsilon_{\mathrm{V}, \text { ave }}=10.9 \%$ (standard deviation, $\mathrm{SD}=6.4 \%$ ), which is within the limited range plausible $\left(\varepsilon_{\mathrm{v}} \leq 19 \%\right.$ for $\left.D_{\mathrm{r}}=100 \%\right)$ given the values of $e_{\min }-e_{\max }$ for the very fine silica sand (Table 1) used in this investigation. The repeated occurrence of localised piping restricted the amount of information on final dilation for the upper region of the soil plug, and precluded a systematic use of these comprehensive PIV analyses throughout the paper. Based on $\varepsilon_{\mathrm{v}, \text { ave }}=10.9 \%$ experienced by the sand plug when applying a high pumping flow rate (tests 3 ), the void ratio, $e$, is estimated to have increased from 0.52 to $\sim 0.69$, which corresponds to a reduction in $D_{\mathrm{r}}$ from $94 \%$ to $\sim 35 \%$. This implies that the sand within the bucket transitioned from a dense to a medium-loose state. Although this would raise questions for the in-service performance of the bucket, experimental evidence in Bienen et al. (2018) suggests that such changes in soil state due to installation may not be permanent.

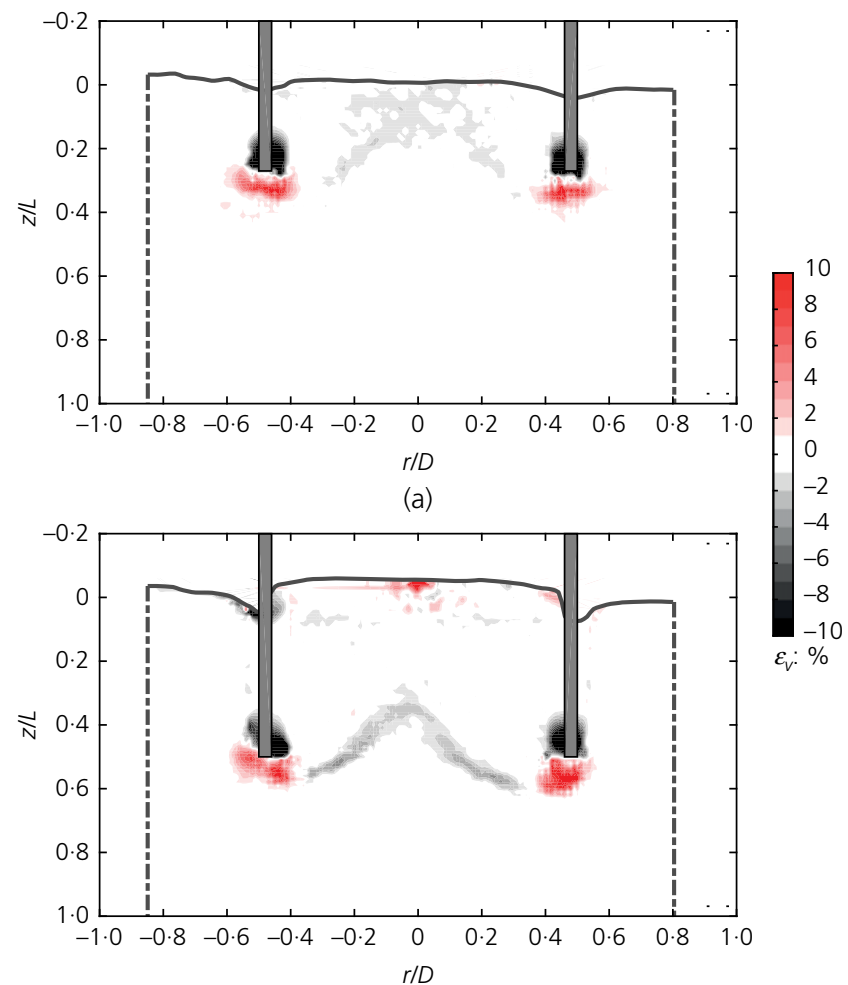

(b)

Figure 19. Total volumetric strain $\varepsilon_{\mathrm{v}}(\%)$ contours during suctionassisted installation for $D_{\mathrm{p}}=5 \mathrm{~m}$ and $D_{\mathrm{r}} \sim 45 \%$ (test 5) at $Z_{\mathrm{PIV}} / L=0.28(\mathrm{a}) ; 0.51(\mathrm{~b})$

Implications for the permeability of the sand within the suction bucket may be considered through the KozenyCarman equation (Chapuis and Aubertin, 2003), which predicts a linear relationship between $k$ and $e^{3} /(1+e)$. Hence, for a change in void ratio from $e=0.52$ to $e \sim 0.69, k$ would have increased by a factor $2 \cdot 1$. This is useful as the ratio of permeability inside the bucket, compared with outside, is an input to predictions of the suction required for installation (e.g. in the Houlsby and Byrne (2005b) method, which for a two-fold increase in permeability would require a relatively modest $15 \%$ increase in suction).

A similar comprehensive analysis was carried out for test 6 $\left(N=40\right.$, and $\left.D_{\mathrm{p}}=2 \mathrm{~m}, \Delta z_{\mathrm{PIV}}=27.8 \mathrm{~mm}\right)$, which also achieved complete installation. The measured $\varepsilon_{\mathrm{v}, \text { ave }}=8.7 \%$ (standard deviation, $\mathrm{SD}=6.5 \%$ ) corresponds to a reduction in $D_{\mathrm{r}}$ from 93 to $\sim 50 \%$, and an increase in internal permeability by a factor of $1 \cdot 7$.

\subsection{Soil plug heave}

Soil plug heave associated with suction bucket penetration may be related to (i) soil displaced inwards by the advancing skirt 
International Journal of Physical Modelling in Geotechnics Volume 20 Issue 3
Observations during suction bucket

installation in sand

Ragni, Bienen, Stanier, O'Loughlin and

Cassidy and/or (ii) loosening of the sand - that is, dilation, inside the bucket. The majority of the soil displaced by the penetrating skirts enters the bucket under suction-assisted installation (insets Figures 7, 9 and 10), with outwards soil movement limited to the self-weight installation stage (inset Figure 4). Loosening of the sand inside the bucket can be attributed to the upwards seepage flow, with the resulting preferential displacement path, and shearing along the skirt (Tran et al., 2005).

Video 1 provided in the supplementary material shows the macro camera view for test 3 (increased pumping flow rate, $q_{\text {pump }}=1178 \cdot 1 \mathrm{~mm}^{3} / \mathrm{s}$ and $D_{\mathrm{r}}=94 \%$ ) where the evolution of the soil plug heave can be observed. The final soil plug surface was located at $h_{\mathrm{plug}} / L=0 \cdot 21$ above the original soil surface (Figure 10), while the volume of soil displaced by the skirts entering the bucket was estimated as $h_{\text {skirt }} / L \sim 0 \cdot 12$ at the final penetration of $z_{\mathrm{fin}} / L=0 \cdot 78$ (assuming that all the soil displaced by the skirts enters the bucket during suction-assisted installation, but only half during self-weight installation). Applying the same logic to test $6\left(N=40, D_{\mathrm{p}}=2 \mathrm{~m}\right.$ and $D_{\mathrm{r}}=93 \%$, see Figure 7), which had an internal plug heave, $h_{\text {plug }} / L=0 \cdot 18$, $h_{\text {skirt }} / L \sim 0.12$ at the final penetration depth of $z_{\text {PIV }} / L=0.77$ is estimated.

Evidently, the observed internal plug heave cannot be explained solely by the volume of soil displaced by the advancing skirts. Assuming that the difference between $h_{\text {plug }}$ and $h_{\text {skirt }}$ is caused by sand dilation, a contribution due to dilation can be defined as $h_{\text {dil }}=h_{\text {plug }}-h_{\text {skirt }}$. It follows that $h_{\text {dil }}$ can be used to estimate the state of the soil plug post-installation, since $\varepsilon_{\mathrm{V}}=h_{\mathrm{dil}} / z_{\text {fin }}$ (where $z_{\text {fin }}$ is the final penetration depth). According to the values reported in Table 2, this leads to an estimated $\varepsilon_{\mathrm{v}}=11.5$ and $7 \cdot 8 \%$ for tests 3 and 6 respectively, which matches reasonably well the average volumetric expansion deduced from the PIV analyses (see previous section 3.2.2.), which were $\varepsilon_{\mathrm{v} \text {,ave }}=10 \cdot 9 \%$ (test 3 ) and $8 \cdot 7 \%$ (test 6). In contrast, analysis of test 5 in the medium dense sample $\left(D_{\mathrm{r}} \sim 45 \%\right.$, Figure 9$)$ indicates that the soil plug underwent contraction, as $h_{\mathrm{dil}} / L=-0 \cdot 01$ at the final penetration $\operatorname{depth}\left(z_{\mathrm{fin}} / L=0 \cdot 64\right)$.

According to these observations, and the data provided in Table 2, it can be concluded that the volume of soil displaced by the advancing skirts is the main cause of the plug heave in the experiments, whereas the sand dilation contribution is only minor, even in dense sand.

Critical hydraulic gradients are thought to have occurred around the skirt tips and within the soil plug. Localised singularities of large soil displacement were observed in the uppermost part of the plug when the highest pumping flow rate was applied (test 3), as well as for tests with $D_{\mathrm{p}}=2 \mathrm{~m}$ (test 6) and
$D_{\mathrm{r}} \sim 45 \%$ (test 5 ). In contrast to the skirt tips, the sand close to the surface is effectively unconfined, so that localised piping took place due to pore pressures reaching the critical value. This caused some of the sand particles to rapidly move upwards, in a direction consistent with the seepage flow. Although masked in the post-processing PIV analyses (see Section 2.4), localised piping phenomena were captured by the micro camera and can be observed in the supplementary material provided with this paper (see Video 2, which shows the installation for test 3 with increased pumping flow rate, and Video 3 for test 6 with $D_{\mathrm{p}}=2 \mathrm{~m}$ ). Note that the onset of localised piping did not result in the end of the suction installation.

\section{Conclusions}

This paper has described an experimental methodology for the investigation of suction bucket installation, facilitated by PIV measurements performed on images captured during tests performed in a geotechnical centrifuge.

The findings presented in this paper confirm the feasibility of suction bucket installation in sand, provide visual insights into the underlying processes, and reveal details regarding the effects of installation on the soil state. In particular, the study shows that

- the deformation mechanism that develops during the suction-assisted phase of bucket installation comprises prevalent inwards motion of soil around the skirt tips, with upwards motion of the soil plug during suction installation. This differs from the self-weight penetration phase, where the soil flow is divided more equally between the inside and outside of the advancing skirt

within the scope of this study, suction-assisted installation in dense samples had the effect of reducing the relative density of the sand within the suction bucket, and consequently increasing its permeability. However, this requires further investigation, since Bienen et al. (2018) concluded that changes in soil state due to installation do not affect the in-service performance

- soil displaced by the penetrating skirts is the main cause of soil plug heave in the experiments presented. A minor contribution can be attributed to sand dilation for the tests carried out in dense samples.

Having demonstrated the viability of investigating suction bucket installation in a centrifuge environment with PIV analyses, the methodology can be now applied to the investigation of the challenging problem of suction bucket installation in layered soils. 
International Journal of Physical Modelling in Geotechnics Volume 20 Issue 3
Observations during suction bucket

installation in sand

Ragni, Bienen, Stanier, O'Loughlin and

Cassidy

\section{Acknowledgements}

This work forms part of the activities of the Centre for Offshore Foundation Systems (COFS), which is currently supported as one of the primary nodes of the Australian Research Council (ARC) Centre of Excellence for Geotechnical Science and Engineering (CE110001009) and as a Centre of Excellence by the Lloyd's Register Foundation. Lloyd's Register Foundation helps to protect life and property by supporting engineering-related education, public engagement and the application of research. The third author is supported by an ARC DECRA Fellowship (DE170100119). The fifth author is the recipient of an ARC Laureate Fellowship (FL130100059). The authors are grateful for these supports.

\section{REFERENCES}

Andersen KH, Jostad HP and Dyvik R (2008) Penetration resistance of offshore skirted foundations and anchors in dense sand. Journal of Geotechnical and Geoenvironmental Engineering 134(1): 106-116.

Bienen B, Klinkvort RT, O'Loughlin CD, Zhu F and Byrne BW (2018) Suction caisson in dense sand, part I: installation, limiting capacity and drainage. Géotechnique 68(11): 937-952, https://doi.org/10.1680/jgeot.16.P.281.

Bolton MD, Gui MW, Garnier J et al. (1999) Centrifuge cone penetration tests in sand. Géotechnique 49(4): 543-552, https://doi.org/10.1680/ geot.1999.49.4.543

Bye A, Erbrich C, Rognlien B and Tjelta TI (1995) Geotechnical design of bucket foundations. In Proceedings of the Offshore Technology Conference, Houston, USA. Offshore Technology Conference, Richardson, TX, USA, pp. 869-883.

Chapuis RP and Aubertin M (2003) On the use of the Kozeny-Carman equation to predict the hydraulic conductivity of soils. Canadian Geotechnical Journal 40(3): 616-628.

Chow SH, O'Loughlin CD, Gaudin C and Lieng JT (2018) Drained monotonic and cyclic capacity of a dynamically installed plate anchor in sand. Ocean Engineering 148: 588-601.

Dewoolkar MM, Ko HY, Stadler AT and Astaneh SMF (1999) A substitute pore fluid for seismic centrifuge modeling. Geotechnical Testing Journal 22(3): 196-210

Dow (Dow Chemical Company) (2002) Methocel Cellulose Ethers. Technical Handbook Dow, Midland, MI, USA.

Ehrmann A, Penner N, Gebhardt CG and Rolfes R (2016) Offshore support structures with suction buckets: parameter fitting of a simplified foundation model. In Proceedings of the International Ocean and Polar Engineering Conference, Rhodes, Greece. International Society of Offshore and Polar Engineers, Mountain View, CA, USA, pp. 52-59.

Erbrich CT and Tjelta TI (1999) Installation of bucket foundations and suction caissons in sand - geotechnical performance. In Proceedings of the Offshore Technology Conference, Houston, USA Offshore Technology Conference, Richardson, TX, USA.

Garnier J, Gaudin C, Springman SM et al. (2007) Catalogue of scaling laws and similitude questions in geotechnical centrifuge modelling. International Journal of Physical Modelling in Geotechnics 7(3) 1-23, https://doi.org/10.1680/ijpmg.2007.070301.

Haigh SK and Madabhushi SPG (2014) Discussion of 'Performance of a transparent flexible shear beam container for geotechnical centrifuge modelling of dynamic problems by Ghayoomi, Dashti and McCartney'. Soil Dynamics and Earthquake Engineering 67: 359-362.
Houlsby GT (2016) Interactions in offshore foundation design. Géotechnique 66(10): 791-825, https://doi.org/10.1680/ jgeot.15.RL.001.

Houlsby GT and Byrne BW (2005a) Design procedures for installation of suction caissons in clay and other materials. Proceedings of the Institution of Civil Engineers - Geotechnical Engineering 158(2): 75-82, https://doi.org/10.1680/geng.2005.158.2.75.

Houlsby GT and Byrne BW (2005b) Design procedures for installation of suction caissons in sand. Proceedings of the Institution of Civil Engineers - Geotechnical Engineering 158(3): 135-144, https://doi.org/10.1680/geng.2005.158.3.135.

Kim JH, Lee ST and Kim DS (2017) Observation of sand movement during bucket installation. International Journal of Physical Modelling in Geotechnics 19(1): 1-14, https://doi.org/10.1680/jphmg.16.00048.

Randolph MF and Gaudin C (2017) Genesis of the national geotechnical centrifuge facility - a 30 year perspective. Australian Geomechanics Journal 52(2): 1-14.

Randolph MF, Jewell RJ, Stone KJL and Brown TA (1991) Establishing a new centrifuge facility. In Centrifuge 91: Proceedings of the International Conference Centrifuge, Boulder, CO, USA (Ko HY and McLean FG (eds)). Balkema, Rotterdam, The Netherlands, pp. 3-9.

Schneider JA and Lehane BM (2006) Effects of width for square centrifuge displacement piles in sand. In Proceedings of the International Conference on Physical Modelling in Geotechnics, Hong Kong, China. CRC Press, Boca Raton, FL, USA, vol. 2, pp. $867-873$.

Senders M and Randolph MF (2009) CPT-based method for the installation of suction buckets in sand. Journal of Geotechnical and Geoenvironmental Engineering 135(1): 14-25.

Senpere D and Auvergne GA (1982) Suction anchor piles - a proven alternative to driving or drilling. Proceedings Offshore Technology Conference, Houston, USA. Offshore Technology Conference, Richardson, TX, USA, pp. 483-494.

Shonberg A, Harte M, Aghakouchak A et al. (2017) Suction bucket jackets for offshore wind turbines: applications from in situ observations. In Proceedings of TC 209 Workshop - 19th International Conference on Soil Mechanics and Geotechnical Engineering, Seoul, South Korea (Shin Y (ed.)). ISSMGE, London, UK, pp. 65-77.

Stanier SA and White DJ (2013) Improved image-based deformation measurement in the centrifuge environment. Geotechnical Testing Journal 36(6): 915-928.

Stanier SA, Blaber J, Take WA and White DJ (2015) Improved image-based deformation measurement for geotechnical applications. Canadian Geotechnical Journal 53(5): 727-739.

Stanier SA, Dijkstra J, Leśniewska D et al. (2016) Vermiculate artefacts in image analysis of granular materials. Computers and Geotechnics 72: 100-113.

Sturm H (2017) Design aspects of suction caissons for offshore wind turbine foundations. In Proceedings of TC 209 WorkshopInternational Conference on Soil Mechanics and Geotechnical Engineering, Seoul, South Korea (Shin Y (ed.)). ISSMGE, London, UK, pp. 45-63.

Tan TS and Scott RF (1985) Centrifuge scaling considerations for fluid-particle systems. Géotechnique 35(4): 461-470, https://doi.org/10.1680/geot.1985.35.4.461.

Taylor RN (1987) Discussion of 'Tan, T.S. and Scott, R.F. (1985). Centrifuge scaling considerations for fluid-particle systems'. Géotechnique 37(1): 131-133, https://doi.org/10.1680/ geot.1987.37.1.131

Teng Y, Stanier SA and Gourvenec SM (2017) Synchronised multi-scale image analysis of soil deformations. International Journal of 
International Journal of Physical Modelling in Geotechnics Volume 20 Issue 3
Observations during suction bucket installation in sand

Ragni, Bienen, Stanier, O'Loughlin and Cassidy
Physical Modelling in Geotechnics 17(1): 53-71, https://doi.org/ 10.1680/jphmg. 15.00058.

Tjelta TI (2015) The suction foundation technology. In Proceedings of the Third International Symposium Frontiers in Offshore Geotechnics, Oslo, Norway (Meyer V (ed.)). CRC Press, London, UK, pp. 85-93. Tran MN (2005) Installation of Suction Buckets in Dense Sand and the

Influence of Silt and Cemented Layers. $\mathrm{PhD}$ thesis, The University of Sydney, Sydney, Australia.
Tran MN and Randolph MF (2008) Variation of suction pressure during caisson installation in sand. Géotechnique 58(1): 1-11, https://doi.org/10.1680/geot.2008.58.1.1.

Tran MN, Randolph MF and Airey DW (2005) Study of sand heave formation in suction caissons using particle image velocimetry (PIV). Proceedings International Symposium Frontiers in Offshore Geotechnics, Perth, Australia (Gourvenec S and Cassidy M (eds)). CRC Press, London, UK, pp. 259-265.

\section{How can you contribute?}

To discuss this paper, please email up to 500 words to the editor at journals@ice.org.uk. Your contribution will be forwarded to the author(s) for a reply and, if considered appropriate by the editorial board, it will be published as discussion in a future issue of the journal.

International Journal of Physical Modelling in Geotechnics relies entirely on contributions from the civil engineering profession (and allied disciplines). Information about how to submit your paper online is available at www. icevirtuallibrary.com/page/authors, where you will also find detailed author guidelines. 